\title{
Hyphenation of a EC / OC thermal-optical carbon analyzer to photo-ionization time-of-flight mass spectrometry: an off-line aerosol mass spectrometric approach for characterization of primary and secondary particulate matter
}

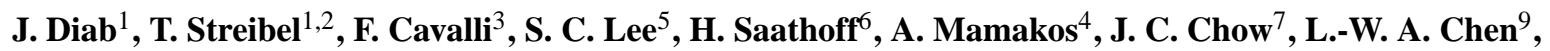 \\ J. G. Watson ${ }^{7}$, O. Sippula ${ }^{1,8}$, and R. Zimmermann ${ }^{1,2}$ \\ ${ }^{1}$ Joint Mass Spectrometry Centre/Chair of Analytical Chemistry, University of Rostock, 18051 Rostock, Germany \\ ${ }^{2}$ Joint Mass Spectrometry Centre/Institute of Ecological Chemistry, Helmholtz Centre Munich, Research Centre for \\ Environmental Health (GmbH), 85764 Munich, Germany \\ ${ }^{3}$ JRC European Commission - Joint Research Centre, Institute for Environment and Sustainability - \\ Air \& Climate Unit, 21027 Ispra, Italy \\ ${ }^{4}$ JRC European Commission - Joint Research Centre, Institute for Energy - Sustainable Transport Unit, 21027 Ispra, Italy \\ ${ }^{5}$ The Hong Kong Polytechnic University, Department of Civil \& Structural Engineering, \\ Hung Hom, Kowloon, Hong Kong, China \\ ${ }^{6}$ Karlsruhe Institute of Technology (KIT), Institute for Meteorology and Climate Research, Atmospheric Aerosol Research \\ Division, 76344 Eggenstein-Leopoldshafen, Germany \\ ${ }^{7}$ DRI-Desert Research Institute, Division of Atmospheric sciences, Reno, NV 89512, USA \\ ${ }^{8}$ Department of Environmental Science, University of Eastern Finland, P.O. Box 1627, 70211, Kuopio, Finland \\ ${ }^{9}$ Department of Environmental and Occupational Health, University of Nevada, Las Vegas, NV 89154, USA
}

Correspondence to: R. Zimmermann (ralf.zimmermann@uni-rostock.de)

Received: 16 September 2014 - Published in Atmos. Meas. Tech. Discuss.: 8 January 2015

Revised: 25 July 2015 - Accepted: 4 August 2015 - Published: 18 August 2015

\begin{abstract}
Source apportionment and characterization of primary and secondary aerosols remains a challenging research field. In particular, the organic composition of primary particles and the formation mechanism of secondary organic aerosols (SOAs) warrant further investigations. Progress in this field is strongly connected to the development of novel analytical techniques. In this study an off-line aerosol mass spectrometric technique based on filter samples, a hyphenated thermal-optical analyzer photo-ionization time-of-flight mass spectrometer (PI-TOFMS) system, was developed. The approach extends the capability of the widely used particulate matter (PM) carbon analysis (for elemental / organic carbon, EC / OC) by enabling the investigation of evolved gaseous species with soft and selective (resonance enhanced multi-photon ionization, REMPI) and non-selective photoionization (single-photon ionization, SPI) techniques. SPI was tuned to be medium soft to achieve comparability with
\end{abstract}

results obtained by the electron ionization aerosol mass spectrometer (AMS). Different PM samples including wood combustion emission samples, smog chamber samples from the reaction of ozone with different SOA precursors, and ambient samples taken at Ispra, Italy, in winter as well as in summer were tested. The EC / OC-PI-TOFMS technique increases the understanding of the processes during thermaloptical analysis and identifies marker substances for the source apportionment. Composition of oligomeric or polymeric species present in PM can be investigated by the analysis of the thermal breakdown products. In the case of wood combustion, in addition to the well-known markers at $\mathrm{m} / \mathrm{z}$ ratios of 60 and 73, two new characteristic masses $(\mathrm{m} / \mathrm{z} 70$ and 98) have been revealed as potentially linked to biomass burning. All four masses were also the dominant signals in an ambient sample taken in winter time in Ispra, Italy, confirming the finding that wood burning for residential heating 
is a major source of PM in winter at this location. The summer sample from the same location showed no influence of wood burning, but seems to be dominated by SOAs, which was confirmed from the comparison with chamber experiment samples. The experiments conducted with terpenes as precursors showed characteristic masses at $\mathrm{m} / \mathrm{z} 58$ and 82, which were not observable in any other emission samples and could serve as a marker for SOA from terpenes.

\section{Introduction}

Atmospheric aerosols are complex mixtures of small solid and liquid particles in the air. They are affecting atmospheric processes and therefore the climate by influencing the radiation balance and cloud formation processes (Fang et al., 2011; Andreae et al., 2004; Charlson et al., 1992; Novakov and Penner, 1993). Furthermore, the particulate phase of aerosols, also referred to as particulate matter (PM), is known to cause adverse health effects by inducing inflammatory reactions and oxidative stress in the airways, leading to cardiovascular and respiratory illnesses and death (Nel, 2005; Samet et al., 2000; Schwartz et al., 2001). For these reasons it is crucial to better understand the origin, formation, and transformation of PM. Due to the multitude of potentially harmful carbonaceous compounds and the unknown effects on the climate, the investigation of the organic carbonaceous part of aerosols is of increasing significance. Carbonaceous aerosols can be subdivided into primary particles, deriving directly from different sources such as pollen, plant debris, particles from biomass- or fossil-fuel burning, and secondary organic aerosols (SOAs), which are formed by gas-phase chemical reactions of volatile organic precursors in the atmosphere (Gelencsér, 2004).

For the analysis of this organic content of PM several methods are used. Methods that focus on the molecular level of analysis can be subdivided into off-line (e.g., gas chromatography-mass spectrometry (GC-MS), liquid chromatography-mass spectrometry (LC-MS), nuclear magnetic resonance; Nolte et al., 2001; Rogge et al., 1993; Schnelle-Kreis et al., 2005, 2007; Jaoui and Kamens, 2003; Samy and Hays, 2013; Vicente et al., 2012) and online (e.g., aerosol mass spectrometer (AMS), aerosol time-offlight mass spectrometer, and laser desorption-ionizationbased techniques; Aiken et al., 2009; Bente et al., 2008; Elsasser et al., 2012; Gard et al., 1997; Ferge et al., 2005b, 2006) methods. Online methods have a real-time character, but the gain with respect to structural information is often low, whereas for example off-line GC-MS measurements reveal a lot of distinct chemical species and individual compounds (Welthagen et al., 2003). Chromatographic methods are sometimes limited by the complexity of the sample, insufficient resolution, and a time-consuming sample preparation (Tobias and Ziemann, 1999; Hallquist et al., 2009). Typ- ically, organic species identified by GC-MS explain $<20 \%$ of the organic mass in PM (Jacobson et al., 2000; Rogge et al., 1993; Schauer et al., 1996).

Methods that classify the PM organic content based on physical and chemical properties are also widely used. They estimate carbon fractions by measuring bulk parameters such as organic carbon (OC) and elemental carbon (EC) via thermal-optical analysis (Watson et al., 2005) and black carbon (BC) via optical or incandescence methods (Moosmüller et al., 2009). The definition of these bulk parameters is operational, and they are often used interchangeably without clear distinction (Andreae and Gelencsér, 2006). For thermaloptical analysis, OC is defined as the less refractory part of the carbonaceous material which evolves at lower temperatures in an inert gas atmosphere; EC represents the more refractory and light-absorbing part which evolves at higher temperatures in an oxygen-containing atmosphere (Seinfeld and Pankow, 2003; Chow et al., 2001, 2007a; Andreae and Gelencsér, 2006). Despite that different thermal evolution protocols may lead to different results (Chow et al., 2001; Han et al., 2013), OC / EC analysis is an important tool for characterizing aerosol and has been used widely in many studies (Aymoz et al., 2007; Chow et al., 2006; Zhang et al., 2011; Watson et al., 1994).

It has been demonstrated that information in addition to bulk parameters OC and EC, the total carbon (TC) amount, and the OC / EC ratio can be obtained from thermal-optical analysis by introducing online measurement of the molecular composition of the evolved gases (Grabowsky et al., 2011). A photo-ionization time-of-flight mass spectrometer (PI-TOFMS) serves as the online analytical technique due to its high sensitivity and fast time resolution. The high sensitivity is required because of the rather low concentration of the individual substances in the evolved gas (an OC / EC analysis is typically carried out with 5-100 $\mu$ g of PM material). The fast response (in seconds) provides an additional advantage to reflect rapid changes in composition of the desorbed gaseous species throughout thermal analysis.

The use of single-photon ionization (SPI) and resonance enhanced multi-photon ionization (REMPI) offers high sensitivity and excludes bulk gases such as helium and water. In the case of REMPI exclusive selectivity for aromatic compounds is achieved via a soft ionization process. The SPITOFMS and REMPI-TOFMS have been successfully applied to different research fields such as the analysis of cigarette smoke, waste incineration plant effluents, wood combustion, pyrolysis processes, and coffee roasting (Mitschke et al., 2005; Hertz et al., 2012; Ferge et al., 2005a; Dorfner et al., 2004; Boesl, 2000; Kohse-Höinghaus and Brockhinke, 2009; Oser et al., 2001; Gullett et al., 2008).

In this work the hyphenation of a thermal-optical carbon analyzer and PI-TOFMS is presented, characterized, and demonstrated for potential applications in aerosol research. To the best of our knowledge such a hyphenated instrument is a novel approach. To better understand the origin, compo- 


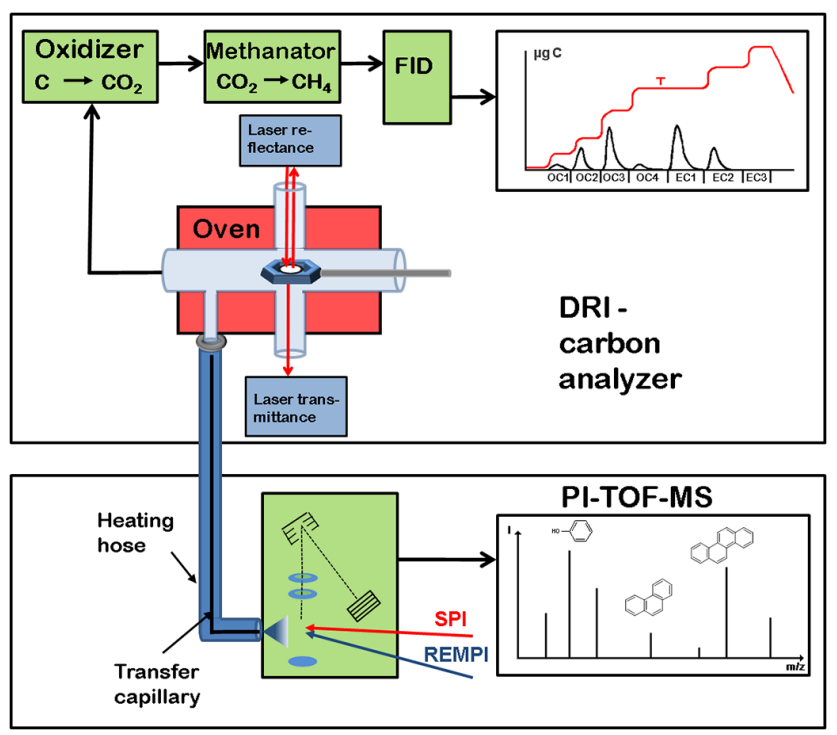

Figure 1. Scheme of the coupling of the Desert Research Institute (DRI) carbon analyzer and the PI-TOFMS.

sition, distribution, and chemical reactions of airborne particulate matter, a variety of samples were investigated as part of this study. Among those, ambient samples were collected from different locations and during different seasons containing primary and secondary aerosols. Emission samples were used to characterize sources that could potentially impact ambient aerosol. In addition, samples from chamber experiments with different precursors were also investigated for chemical composition of secondary particles.

One aim of this study is the identification of major emission sources and the assessment of their contribution to ambient aerosols. For the organic content of ambient primary particles (primary organic aerosols), it is possible to assign specific substances or compound classes (i.e., markers) to corresponding primary sources and conduct source apportionment based on chemical mass balance. Progress has been made in this field with GC-MS measurements (Schauer and Cass, 2000; Schauer et al., 1996; Cass, 1998; Rogge et al., 1998; Chen et al., 2012; Chow et al., 2007b).

The organic content of secondary particles (secondary organic aerosol, SOA) can account for up to $88 \%$ of the organic carbon fraction in hours of the highest photochemical activity (Lim and Turpin, 2002). They can derive from nucleation of gaseous precursors, condensation of gases on particles or chemical reactions in the troposphere (Hallquist et al., 2009; de Gouw et al., 2005). The composition of SOA is very complex, as many thousands of structurally different organic oxygenates are formed from volatile organic compounds (VOCs) which contribute more or less to the SOA formation (Hallquist et al., 2009; Atkinson and Aschmann, 1993). The precursors for SOA formation can be derived from either anthropogenic sources (e.g., toluene) or biogenic sources (e.g., monoterpenes such as $\alpha$ - and $\beta$-pinene), whereas the latter sources are emitted in higher quantities on a global scale (Larsen et al., 2001). Terpenes are released by a variety of plants and trees, particularly conifers. Depending on whether the $\mathrm{C}=\mathrm{C}$ double bond is located inside or outside the ring they are referred to as endocyclic or exocyclic terpenes (Larsen et al., 2001). They have higher PM-forming potential than typical aromatic species, such as xylene (Seinfeld and Pankow, 2003) and play a major role in aerosol formation, especially in rural areas and in times of high photochemical activity.

A part of the SOA mass can also result from oligomerization and/or polymerization by heterogenous reactions of particle-associated substances and relatively low-volatile species, which could be the reaction products from the oxidation of VOCs. This leads to the formation of high-molecularweight products (Tolocka et al., 2004; Jang et al., 2003; Surratt et al., 2006; Gao et al., 2004). These macromolecular species include humic-like substances (HULIS) with structure similar to humic and fulvic acids. HULIS are also derived from combustion processes involving plant material and biomass burning (Mukai and Ambe, 1986; Zappoli et al., 1999; Graber and Rudich, 2006). Although the structure of HULIS are still unclear, they are supposed to consist of aliphatic and aromatic structures with polyacidic character and other functional groups attached (Mukai and Ambe, 1986).

The influence of a precursor VOC on the formation of SOA depends not only on its structure but also on the ambient conditions such as temperature or relative humidity (Hallquist et al., 2009; Seinfeld and Pankow, 2003). Smog chamber experiments are a useful tool to simulate the complex atmospheric processes producing SOA. They provide critical information for atmospheric models (Fang et al., 2011; Jaoui et al., 2008). The unknown comparability to real atmospheric processes and products, due to much higher concentrations of precursors and oxidants in laboratory studies, lack of other VOCs, and effects of the chamber walls, still presents a major challenge for smoke chamber studies (Jaoui et al., 2008; Hallquist et al., 2009).

\section{Experimental setup}

\subsection{Description of the assembling}

The assembling of the hyphenation between the thermaloptical carbon analyzer and the PI-TOFMS is shown in Fig. 1 (photographs of the assembling are given in Fig. S1a and b in the Supplement). A description of the principal setup concept has already been given in a previous publication (Grabowsky et al., 2011).

In summary, the measurement unit consists of two parts, a thermal-optical carbon analyzer (Atmoslytic Inc., Calabasas, California, USA) and a photo-ionization time-of-flight mass spectrometer. 


\subsubsection{Thermal-optical carbon analyzer}

For the carbon determination of the samples collected on quartz-fiber filters, a punch of the filter is placed on the sample holder of the carbon analyzer, which is located inside a quartz tube. The oven is heated stepwise according to the preset temperature program. In this study, the IMPROVE_A temperature protocol was applied. The first four temperature steps $\left(140,280,480\right.$, and $580^{\circ} \mathrm{C}$ corresponding to $\mathrm{OC} 1$, $\mathrm{OC} 2, \mathrm{OC} 3$, and OC4 fractions, respectively) are performed while pure helium is streaming through the apparatus as carrier gas and the following three steps $\left(580,740\right.$, and $840^{\circ} \mathrm{C}$ corresponding to $\mathrm{EC} 1, \mathrm{EC} 2$, and $\mathrm{EC} 3$ fractions, respectively) are carried out in a $\mathrm{He} / 2 \% \mathrm{O}_{2}$ atmosphere. The released carbonaceous species are led through a heated oxidizer (manganese oxide) and are completely oxidized to $\mathrm{CO}_{2}$. The $\mathrm{CO}_{2}$ is subsequently reduced quantitatively to methane via a nickel catalyst. The amount of methane is measured by a flame ionization detector (FID) and represents the total amount of carbon of each fraction. The signal is calibrated by $1 \mathrm{~mL}$ of a standard mixture of $5 \%$ methane in helium. The next temperature is not initiated until the FID signal reaches the baseline or stays constant for a certain time, which is why the duration of each temperature step differs, depending on the respective amount of carbon.

The optical part of the carbon analyzer includes a $\mathrm{He} / \mathrm{Ne}$ laser and two detectors, one to measure the reflectance of the sample filter and one for a transmission measurement. This optical measurement is necessary for the correction of the sum OC and sum EC amount, because a part of the organic species chars during the desorption steps, deposits on the filter, and is then later falsely determined as elemental carbon. As a consequence, the initial laser reflection or transmission signal of the filter, measured before the temperature program started, but after the filter was inserted into the laser beam inside the oven, goes down. This is caused by the lightabsorbing character of the char. After the switch to the $\mathrm{He} / \mathrm{O}_{2}$ carrier gas, the laser signal rises again due to the combustion of the char and the EC. Only the amount of carbon that was measured in the EC1 step after the laser signal reaches its initial value is assigned to EC, the one before is assigned to OC (Chow et al., 1993, 2001).

\subsubsection{Time-of-flight mass spectrometer}

A reflectron time-of-flight (TOF) mass spectrometer (Stefan Kaesdorf, Munich, Germany) equipped with a homebuilt photo-ionization setup has been utilized. The sample is introduced via an interface consisting of a heated fused silica capillary running inside a heated copper cone ending directly above the center of the ionization region. The gaseous sample is ionized by photons generated by a Nd-YAG laser (Spitlight 400, Innolas GmbH, Krailling, Germany). For REMPI the fourth harmonic $(266 \mathrm{~nm})$ is employed. For SPI the third harmonic $(355 \mathrm{~nm})$ is used. These laser pulses are frequency tripled by focusing them into a gas cell filled with ultrapure xenon at a pressure of $800 \mathrm{~Pa}$, yielding VUV (vacuum ultraviolet) light of $118 \mathrm{~nm}$ (Mühlberger et al., 2001; Butcher et al., 1999; Maker and Terhune, 1965; Vidal, 1987).

Despite being a soft ionization method, it is possible to tune SPI in order to enable partial fragmentation. For this, the $118 \mathrm{~nm}$ beam is focused directly underneath the inlet needle. The resulting high VUV-photon densities are sufficient to cause two photon processes to some extent, which leads to some fragmentation of organic molecules, while the molecular ion signals are still visible. This enables one to obtain some structural markers on the ionized species as observable in the AMS approach with electron ionization. This SPI setting has been chosen for the present study, because it facilitates the identification of AMS marker substances for the comparison of ambient air particulate samples and emission source samples.

Quantification may be carried out by external calibration with standard gas mixtures (Adam and Zimmermann, 2007; Eschner and Zimmermann, 2011). Alternatively, if the cross sections for the used wavelength are known, the compounds can be quantified using a toluene gas standard as reference (Adam and Zimmermann, 2007).

For the data acquisition, a preamplifier (Femto Messtechnik $\mathrm{GmbH}$, Berlin) and a two channel PC transient recorder card were used (Type: AP240 Acqiris, Geneva, Switzerland). Due to the fixed laser frequency of $20 \mathrm{~Hz}, 20$ mass spec$\operatorname{tra~s}^{-1}$ were acquired. However, 80 mass spectra were internally averaged on the transient recorder card before storing $(0.25 \mathrm{~Hz}$ final measurement rate).

\subsection{Hyphenation of the EC / OC analyzer to the PI mass spectrometer}

For the hyphenation of the two instruments, a fraction of gaseous compounds has to be bypassed after the oven, but also prior to the oxidation unit. Since the sample holder and oxidizer are located in the same quartz tube (see Fig. S1c in the Supplement), the quartz tube is modified to include a side arm with an outer diameter of $1 / 8 \mathrm{in}$. and a length of $90 \mathrm{~mm}$ at the point where the oven ends (see Fig. S1d in the Supplement). The side arm extends into an aluminum box (Fig. S1g and e), which is heated to $230^{\circ} \mathrm{C}$. Inside the aluminum box, the connection of the quartz tube to a deactivated fused silica capillary $(320 \mu \mathrm{m}$ ID, BGB Analytik Vertrieb $\mathrm{GmbH}$, Rheinfelden) is located in order to transfer the gaseous species into the ion source of the mass spectrometer via the inlet needle described earlier (Fig. S1f). The capillary is located inside a heating hose which is heated to $235^{\circ} \mathrm{C}$ and is linked to the aluminum box. By this bypass approximately $5 \mathrm{~mL} \mathrm{~min}^{-1}$ of the $50 \mathrm{~mL} \mathrm{~min}^{-1}$ flowing through the carbon analyzer are transferred to the mass spectrometer system. 

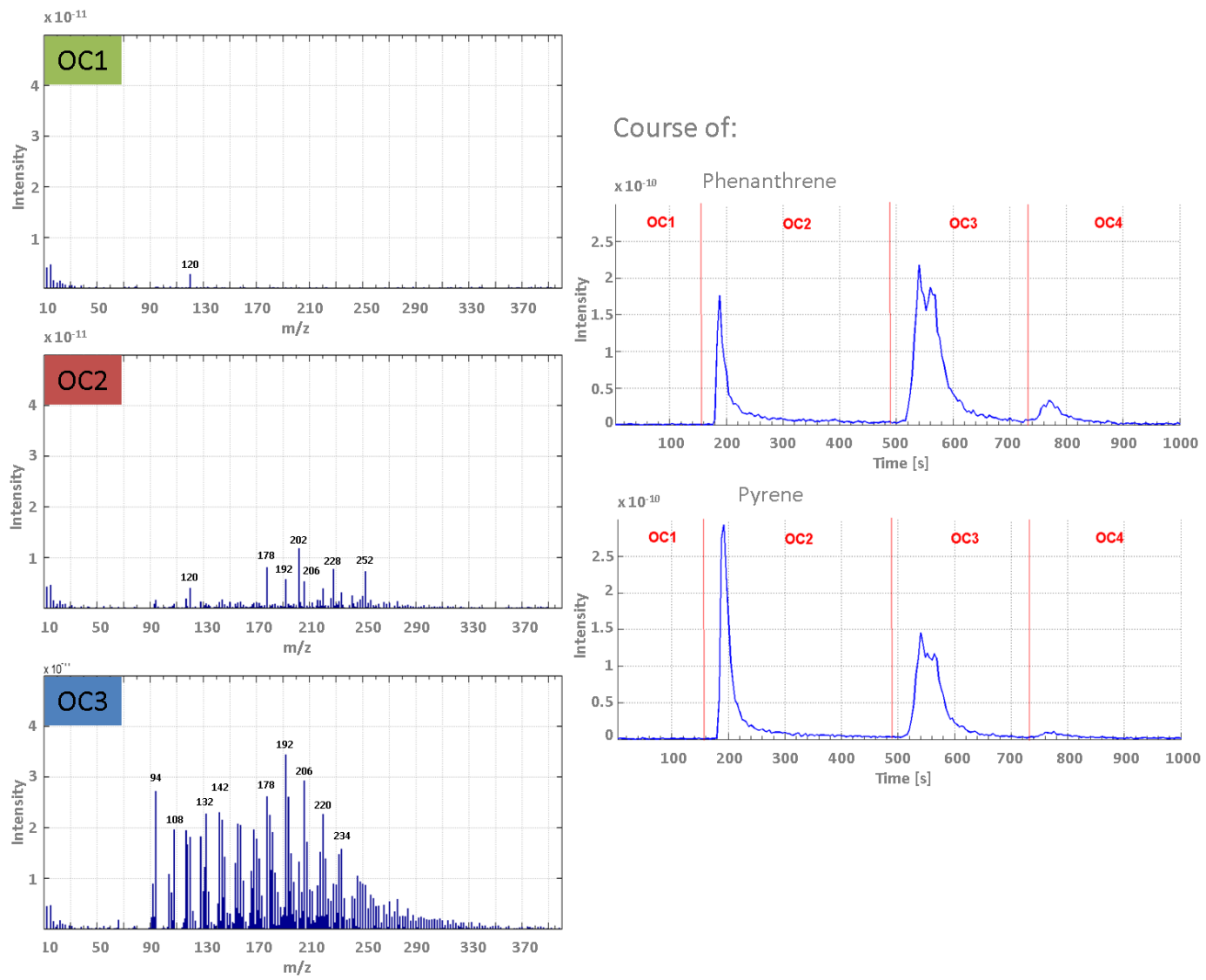

Figure 2. Measurement of the NIST urban dust standard material with EC / OC-REMPI-TOFMS: mass spectra of the first three OC steps (left panel) and the courses of phenanthrene and pyrene (right panel).

\subsection{Characterization of the hyphenated EC / OC-PI-TOFMS system}

With calibration gas standards, the limit of detection (signalto-noise $(S / N)$ ratio $=3$ for an average of 100 spectra) for SPI-TOFMS has been determined to be $1 \mathrm{ppb}(v / v)$ for benzene, $2 \mathrm{ppb}$ for toluene, and $2.3 \mathrm{ppb}$ for trimethylbenzene. For REMPI-TOFMS it is $43 \mathrm{ppb}$ for benzene, $5 \mathrm{ppb}$ for toluene, and $2 \mathrm{ppb}$ for trimethylbenzene $(S / N=3)$. In both cases 100 spectra are averaged. The mass resolution $(m / \Delta m)$ of the PI-TOFMS system is approximately 1000 calculated from the benzene signal using the FWHM (full width at half maximum) method.

Further analyses for the evaluation of the EC / OC-PITOFMS setup were carried out with a NIST (National Institute of Standards and Technology) urban dust standard reference material 1649a (Fig. 2) which is well characterized for contents of polycyclic aromatic species. The samples were weighed and introduced into the analyzer in prebaked silver capsules which were attached on the sample holder. The material is certified to contain $177 \mathrm{mg} \mathrm{g}-1 \mathrm{TC}$, and the actual determination of TC with the employed setup is within a $10 \%$ difference $(190 \mathrm{mg}$ g-1). The majority of the organic carbon was desorbed during the OC2 and especially OC3 steps. The average REMPI-TOFMS spectrum for OC2 shows masses corresponding to polycyclic aromatic hydrocarbon (PAH) and alkylated PAH. In the OC3 phase, both small and large aromatic species are visible in the REMPITOFMS spectrum. The smaller species (e.g., $m / z$ 94: phenol, $m / z$ 108: cresols) are a result of thermal decomposition of larger structures. The same PAH compounds (such as phenanthrene and pyrene) appear to be released during different temperature steps (Fig. 2). The SPI-TOFMS spectrum of OC3 also shows prominent peaks of small unsaturated hydrocarbons $(m / z 42,56,68,82)$, supporting the idea that larger molecular structures are thermally cracked forming alkenes. Alkenes are typical cracking products of hydrocarbons and oxy-hydrocarbons.

The coefficient of variance of the 10 most abundant masses ranges from $7.7 \%(m / z 128)$ to $18.5 \%(m / z 202)$ for EC / OC-REMPI-TOFMS and $6.4 \%(\mathrm{~m} / \mathrm{z} 68)$ to $13.9 \%$ $(\mathrm{m} / z$ 96) for EC / OC-SPI-TOFMS, as calculated from five replicates. Pyrene $(m / z$ 202) was chosen for the calculation of the limit of quantification of this hyphenated system because the REMPI setup is highly selective for this compound with the wavelength that was used $(266 \mathrm{~nm})$. The other PAH 


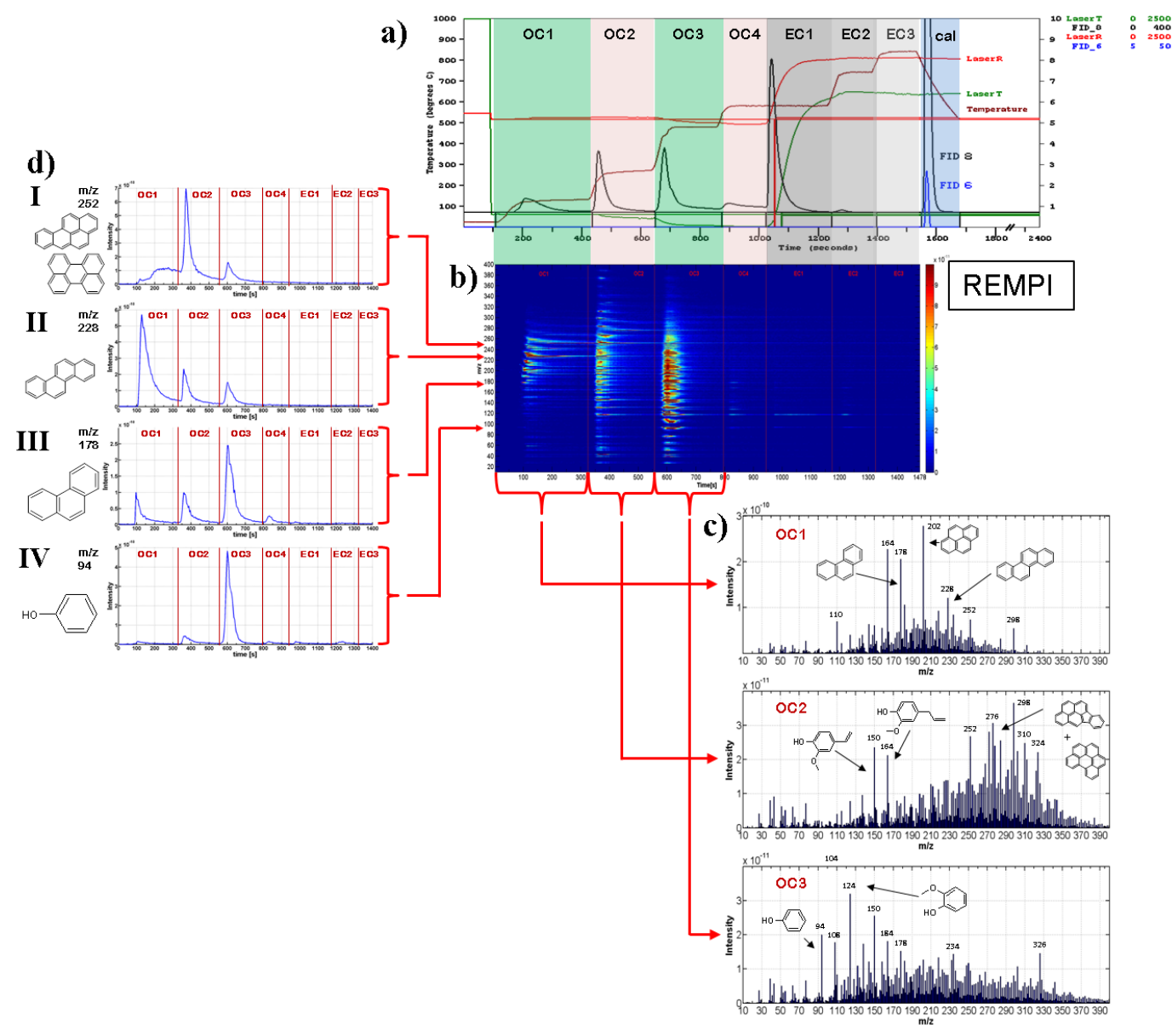

Figure 3. Description of the data structure and analysis of the evolved gas during the EC / OC analysis of a wood combustion emission sample measured by REMPI-TOFMS: (a) thermogram of the carbon analyzer, (b) $\mathrm{m} / \mathrm{z}$ time-contour plot over the whole duration of the OC / EC analysis, (c) averaged mass spectra of the first three OC steps, and (d) courses of different $m / z$ ratios over the whole duration of the $\mathrm{OC} / \mathrm{EC}$ analysis

with an $\mathrm{m} / \mathrm{z}$ ratio of 202, fluoranthene, has only a negligible cross section and can therefore be disregarded. The same scenario is obtained for phenanthrene and anthracene $(\mathrm{m} / \mathrm{z}$ 178). In this case the contribution of anthracene can be ignored. The calculations were carried out by assuming that the all pyrene on the particles is desorbed during OC2 and the signal with OC3 is caused by pyrolytic decomposition of larger molecules. Comparing the signal evolving in the OC2 phase to the reported pyrene content by NIST gives a limit of quantification of $0.09( \pm 0.015) \mathrm{ng}$, when using averaged spectra over the minimum OC-phase time ( $150 \mathrm{~s}$ ) and a $S / N$ ratio of 3. If the OC3 signal contains a portion of pyrene that has not been desorbed at lower temperatures (e.g., due to higher adsorption forces at the particle surface), the limit of quantification would be even lower.

\subsection{Description of the data structure}

The carbon analyzer measurement yields a thermogram (Fig. 3a), which shows the course of the temperature, the carbon content of each fraction obtained by the FID measurement and the laser correction, and both the transmission and reflectance signal. With the help of the mass spectrometer it is possible to follow the chronological development of all the evolving gaseous species, characterized by their $\mathrm{m} / \mathrm{z}$ ratio. A two-dimensional contour plot is obtained as shown in Fig. 3b, where the $m / z$ ratios are plotted over time and therefore over each temperature step. In this manner the twodimensional plot can Supplement the thermogram of the carbon analyzer. The intensities of the measured substances are color coded.

There are two different ways to get a deeper insight into the data. First, average mass spectra can be drawn for a temperature step. This is shown in Fig. 3c for the $\mathrm{OC} 1, \mathrm{OC} 2$, and OC3 steps for measurements with REMPI-TOFMS. In the OC4 and EC steps, a negligible amount of gaseous species was detected. This leads to the assumption that almost all organic species have been released during the first three OC fractions. There is a broader mass spectrum for OC 3 than 
for $\mathrm{OC} 1$ and $\mathrm{OC} 2$, indicative of the desorption of larger molecules of lower volatility due to the higher temperature as well as smaller fragments from pyrolytic decomposition of larger non-volatile organic structures. The analysis of this kind of thermal breakdown product is usually done with pyrolysis-gas chromatography mass spectrometry (Faix et al., 1987). In this study the thermal breakdown products in OC3 can also be used to draw conclusions with respect to the macromolecules, which are not detectable intact due to their low volatility. For example, in Fig. $3 \mathrm{c}$ in the OC3 section a lot of phenolic compounds can be seen such as phenol $(m / z$ 94), guaiacol $(m / z 124)$, and vinylguaiacol $(m / z 150)$, which lead to the conclusion that these are thermal fragments of lignin, a typical wood component (Faix et al., 1987). The OC1 and OC2 steps in contrast to the OC 3 step are dominated by desorption of smaller molecules.

Second, time traces of single $m / z$ ratios can be drawn, as exemplified in Fig. 3d. In course IV it can be seen that almost all phenol is released in the OC3 step, confirming that phenol is not originally present on the PM-loaded filter but rather formed as a thermal breakdown product of larger, oxygenated molecules. In course III the peaks of the $m / z 178$, phenanthrene, in the $\mathrm{OC} 1$ and $\mathrm{OC} 2$ steps indicate desorption of phenanthrene, while the large and broad peak in the OC3 step predominately stands for the release by thermal breakdown. In course II $(m / z 228)$ desorption predominates and in course $\mathrm{I}(\mathrm{m} / \mathrm{z} 252)$ most of the substance is desorbed in the OC2 step, though the vapor pressure was high enough to enable a small release even in OC1. Desorption of larger PAHs or other non-volatile organic species in OC3 is possible, though they typically account for a small fraction of organic compounds.

\section{Application to exemplary filter PM samples}

The ambient PM samples analyzed in this study were acquired from the Institute for Environment and Sustainability at the European Commission Joint Research Center in Ispra, Italy. They represent a rural background site at the northwest edge of the Po Valley. Samples were taken for $24 \mathrm{~h}$ with a flow rate of $1 \mathrm{~m}^{3} \mathrm{~h}^{-1}$. The winter sample was taken on the 18 January 2010 and the summer sample on the 15 July 2010. A detailed description of the ambient samples can be found in Gilardoni et al. (2011).

The source samples representing wood combustion were taken during a measurement campaign in Straubing, Germany, where different furnaces and several types of wood were used. For the wood combustion sample used here spruce wood was burned in a stove (Blueline, Buderus, Germany).

The smog chamber experiments were performed at the Department of Civil \& Structural Engineering of Hong Kong Polytechnic University in Hong Kong and at the Atmospheric Aerosol Research Division of the Institute for Meteorology and Climate Research at the Karlsruhe Institute of Technol- ogy (KIT, Germany). Both chamber experiments were conducted at room temperature $\left(23-24^{\circ} \mathrm{C}\right)$, with added ozone and in the absence of $\mathrm{NO}_{x}$ or $\mathrm{SO}_{2}$. At the Hong Kong tests, $\alpha$-pinene, $\beta$-pinene, and isoprene were used as precursors with concentrations of $100-500 \mathrm{ppm}$ and ozone concentrations of $0.1 \mathrm{ppm}$. At the Karlsruhe tests, $\alpha$-pinene was used with a concentration of $2.2 \mathrm{ppm}$ and ozone concentrations of $25 \mathrm{ppm}$ and $6 \mathrm{ppm}$, respectively. A detailed composition of the experiment parameters of both chambers is given in Table S1 in the Supplement. The samples were stored in gastight dishes and shipped over night with refrigeration.

All spectra from EC / OC-PI-TOFMS analysis of the ambient and source samples are available in the Supplement (Figs. S3-S13), along with a two-dimensional overview of all OC steps and $m / z$ ratios, averaged mass spectra of the first three OC steps, and the normalized average mass spectra of $\mathrm{OC} 1-\mathrm{OC} 3$.

\subsection{Ambient samples}

The contour plots ( $m / z$ over EC / OC measurement time) of the ambient samples taken in Ispra, Italy, reveal substantial differences between summer and winter PM (Fig. 4). The amount of carbon and of evolving gaseous species of the winter sample is higher than the summer sample. The difference the between summer and winter samples in regard to the aromatic content is very striking as almost no aromatics can be found in the summer sample but the amount of aromatics in the winter sample is rather high. On the other hand, the summer sample contains several non-aromatic species evolving in the OC2 and OC 3 fractions. The ratio between OC and $\mathrm{EC}$, however, is similar for both samples, with the organic content dominating.

In Fig. 5 averaged SPI- and REMPI-TOFMS spectra of the first three OC fractions of the ambient winter PM sample are given and compared with the respective patterns from the wood combustion emission PM sample representing the starting phase of the wood combustion process. This comparison is motivated from literature data as Alfarra et al., 2007 found with radiocarbon measurements that wood burning can attribute up to $94 \%$ of ambient organic mass in winter time. The wood burning emission sample is highly dominated by organic species, and the OC fractions account for $76 \%$ of the released carbon. A dominance of the OC fractions was also found in experiments analyzing wood stove emissions fueled with wood from different tree species (Fine et al., 2004). The OC levels ranged between 43.6 and $77.8 \%$ of $\mathrm{PM}_{2.5}$ (averaged $58 \%$ ) and EC ranged between 3.3 and $22.8 \%$ (averaged $12 \%$ ). Chow et al., 2011 also reported OC and EC abundances of $22-68 \%$ and $4-33 \%$ of $\mathrm{PM}_{2.5}$, respectively.

Many aromatic compounds are released during wood burning, such as phenanthrene $(\mathrm{m} / \mathrm{z} 178)$, benzophenone $(m / z$ 182), pyrene $(m / z 202)$, benz(a)anthracene or chrysene $(\mathrm{m} / \mathrm{z} 228)$, benzo(a)pyrene or benzo(k)fluoranthene $(\mathrm{m} / \mathrm{z}$ 252), and benzo(ghi)perylene or indeno(1,2,3-cd)pyrene 

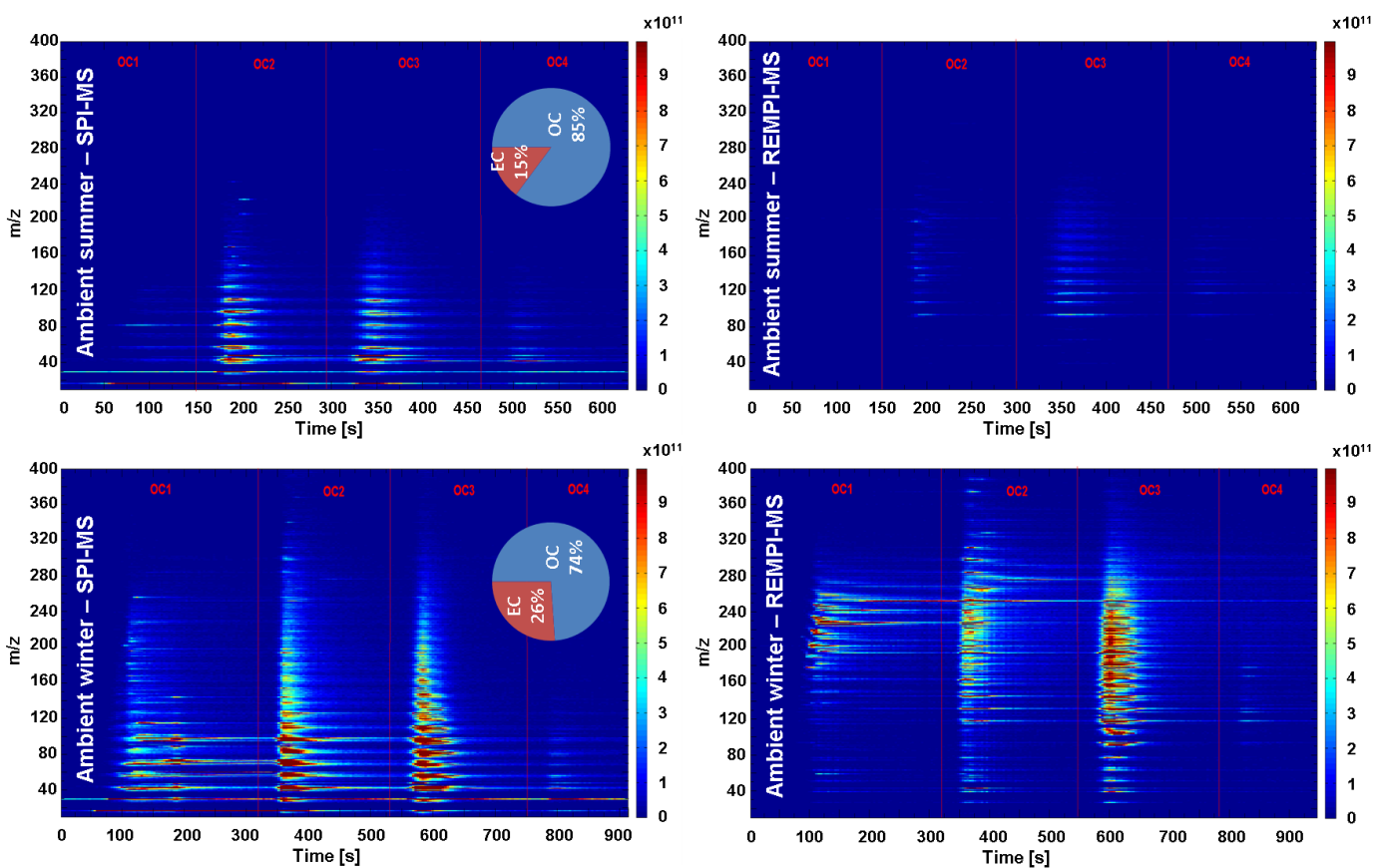

Figure 4. Plots of the EC / OC-PI-TOFMS $\mathrm{m} / \mathrm{z}$ time contour (REMPI and SPI ionization method) of typical summer and winter ambient PM samples (Ispra, Italy).
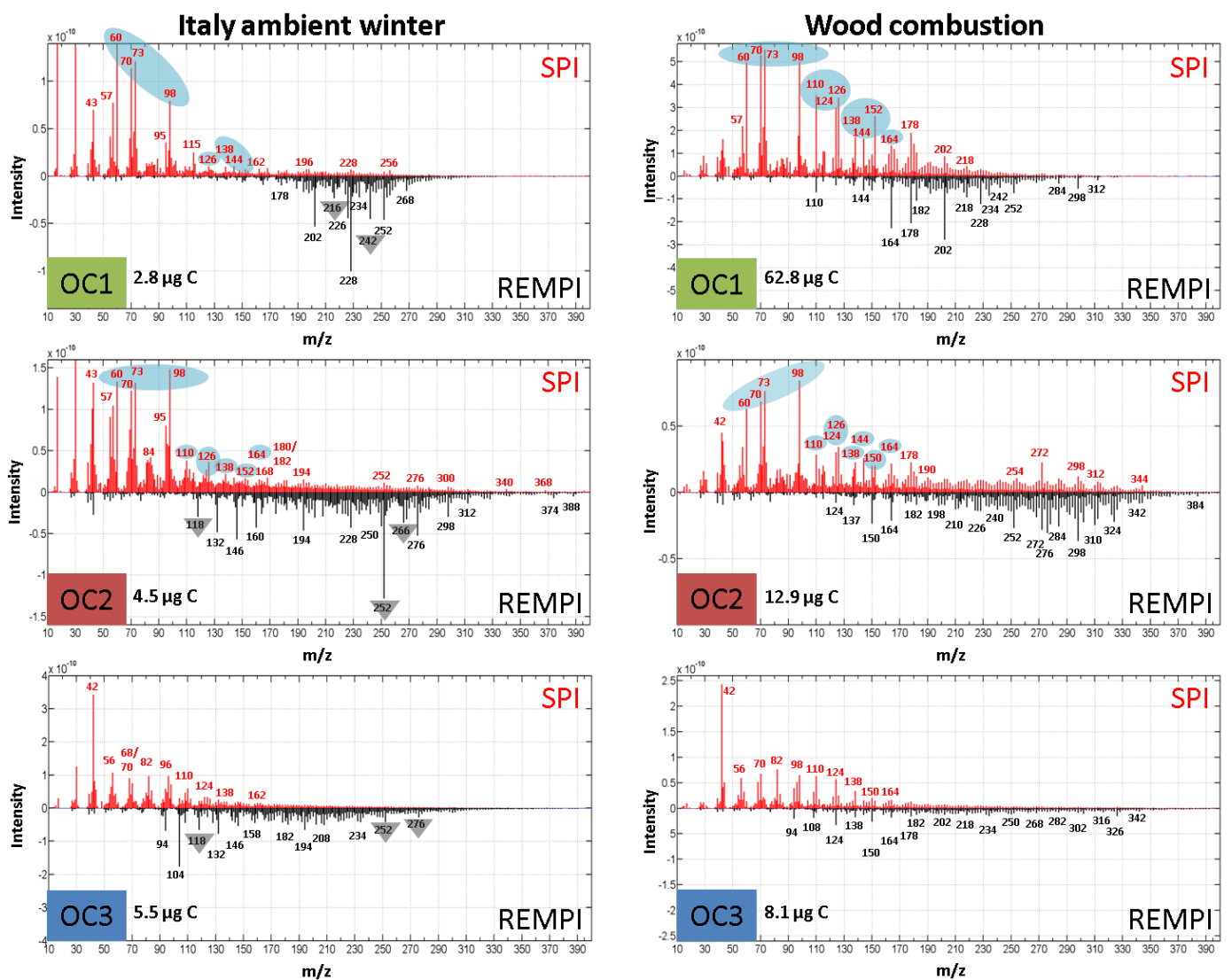

Figure 5. Comparison of the EC / OC-PI-TOFMS data (SPI - red/positive and REMPI - black/negative) for the wood combustion emission PM sample and the ambient PM winter sample from Ispra. The averaged mass spectra for OC1, OC2, and OC3 are shown. 
Table 1. Tentative assignment of the obtained EC / OC-PI-TOFMS mass signals for REMPI and SPI experiments. The assignment is based on previous studies using these ionization techniques, chromatographic analyses, and literature data (Fine et al., 2002, 2004; Ferge et al., 2005b; McDonald et al., 2000; Nolte et al., 2001; Rogge et al., 1993; Williams et al., 2006, 2007; Aiken et al., 2009; Elsasser et al., 2012; Hennigan et al., 2011). A more comprehensive list can be found in the Supplement.

\begin{tabular}{|c|c|c|c|}
\hline$m / z$ & $\begin{array}{l}\text { Tentative assignation of detected } \\
\text { compounds by EC / OC-SPI-TOFMS }\end{array}$ & $m / z$ & $\begin{array}{l}\text { Tentative assignation of detected } \\
\text { compounds by EC / OC-REMPI-TOFMS }\end{array}$ \\
\hline 17 & Ammonia (from $\mathrm{NH}_{4} \mathrm{NO}_{3}$ ) & 94 & Phenol \\
\hline 30 & Nitrogen monoxide (from $\mathrm{NH}_{4} \mathrm{NO}_{3}$ ) & 108 & Methylphenol \\
\hline 42 & Propene & 118 & Indene, benzofuran \\
\hline 56 & Butene, propenal (acrolein) & 124 & Guaiacol \\
\hline 60 & $\mathrm{C}_{2} \mathrm{H}_{4} \mathrm{O}_{2}^{+}$ & 137 & Nitrotoluene \\
\hline 68 & Furan, isoprene & 138 & Methylguaiacol \\
\hline 70 & Pentene, butenal & 144 & Naphthol \\
\hline 82 & Methylfuran & 150 & Vinylguaiacol \\
\hline 94 & Phenol & 164 & Allylguaiacol (eugenol) \\
\hline 96 & Furfural & 174 & Methoxy naphthol \\
\hline 98 & Furfuryl alcohol & 178 & Phenanthrene \\
\hline 108 & Methylphenol & 182 & Syringaldehyde, ethylsyringol \\
\hline 110 & Benzenediol, acetylfuran & 192 & Methylphenanthrene \\
\hline 112 & Octene & 196 & Propyl syringol \\
\hline 122 & Hydroxybenzaldehyde, benzoic acid, etc. & 200 & Dibenzofuranol \\
\hline 124 & Guaiacol & 202 & Pyrene \\
\hline 126 & Hydroxymethylfurfural & 210 & Syringyl acetone \\
\hline 138 & Methylguaiacol & 218 & Phenyl methyl naphthalene \\
\hline 144 & Octanoic acid, naphthol & 226 & Cyclopenta[cd]pyrene, benzo[ghi]fluoranthene \\
\hline 150 & Vinylguaiacol, coumarylalcohol & 228 & Chrysene, benz[a]anthracene \\
\hline 152 & Ethylguaiacol, vanillin & 234 & Retene \\
\hline 162 & Levoglucosan & 242 & Methylchrysene \\
\hline 164 & Allylguaiacol (eugenol) & 252 & PAH (benzo[a]pyrene, benzo[k]fluoranthene, etc.) \\
\hline 166 & Propylguaiacol, acetovanillone & 276 & Benzo[ghi]perylene, indeno[1,2,3-cd]pyrene \\
\hline 168 & Vanillic acid, methyl syringol & 278 & Dibenz[a,h]anthracene \\
\hline 178 & Coniferyl aldehyde & 300 & Coronene \\
\hline 180 & Guaiacyl acetone, coniferyl alcohol & 302 & PAH (benzo(a)perylene, etc.) \\
\hline 194 & Propenyl syringol & & \\
\hline 272 & Methyl deisopropyldehy droabietate & & \\
\hline 284 & Stearic acid, heptadecanoic acid methyl ester & & \\
\hline 312 & Eicosanoic acid & & \\
\hline
\end{tabular}

( $m / z$ 276). A list of prominent $m / z$ ratios present in the wood combustion emission sample and proposals for their structure are given in Table 1. The most likely structures are assigned according to the literature of wood combustion emissions (Fine et al., 2004; McDonald et al., 2000; Nolte et al., 2001; Fine et al., 2002; Hennigan et al., 2011) and to the characteristics of the ionization technique. A more comprehensive list containing all $\mathrm{m} / \mathrm{z}$ ratios and propositions for all important species can be found in the Supplement (Table S3).

Many cellulose and lignin breakdown products can be identified from the SPI-TOFMS spectra as well. These include furan and its derivatives: furan $(\mathrm{m} / \mathrm{z} 68)$, methylfuran $(m / z$ 82), furfural $(m / z$ 96), furfuryl alcohol $(\mathrm{m} / \mathrm{z}$ $98)$, acetylfuran or methylfurfural $(\mathrm{m} / z, 110)$, and hydroxymethylfurfural $(m / z 126)$ as typical cellulose pyrolysis markers. Furthermore, phenol $(\mathrm{m} / z$ 94) and its derivatives cresols $(m / z 108)$, dihydroxybenzenes $(m / z 10)$, guaiacol
( $m / z$ 124), methylguaiacol $(\mathrm{m} / \mathrm{z} 138)$, vinylguaiacol $(\mathrm{m} / \mathrm{z}$ $150)$, ethyl- or dimethylguaiacol $(m / z 152)$, allylguaiacol $(m / z 164)$, and propylguaiacol $(m / z 166)$ appear as typical markers of lignin pyrolysis.

Furthermore, the fragments with a $m / z$ ratio of 60 and 73 appearing prominently in $\mathrm{OC} 1$ and $\mathrm{OC} 2$ are known to be mass spectrometric wood combustion markers (e.g., fragments of levoglucosan, resolved by AMS) in both wood burning smoke and ambient air (Hennigan et al., 2011; Elsasser et al., 2012; Aiken et al., 2009; Alfarra et al., 2007; Lee et al., 2010). Additionally, the $m / z$ ratios of 70 and 98 (furfuryl alcohol) seem to be very prominent and characteristic in both OC steps and could act as wood burning markers. The four fragments can be seen not only in the starting-phase sample for wood combustion but also in all investigated burning phases, i.e., the three nominal load-phase samples. Additional data from the starting phase (wood combustion I) and 
one of the nominal load-phase samples (wood combustion II) are shown in the Supplement (Figs. S5 and S6). Although the overall signal intensities go down in the nominal load phases, the four characteristic wood combustion markers $(\mathrm{m} / \mathrm{z}, 60$, 70,73 , and 98) emerge more intensively compared to the other compounds (furan and guaiacol derivatives). This is supporting the robustness of the four wood combustion indicator mass peaks, because they are released during the whole combustion process.

The SPI mass spectrum for the $\mathrm{OC} 1$ fraction of the ambient winter PM sample (Fig. 5 left) shows strong $\mathrm{m} / \mathrm{z}$ 17 (NH3) and $m / z 30$ (NO) peaks from ammonium. The REMPI spectrum of OC1 depicts a distribution of PAH $(\mathrm{m} / z$ 178-268) with $m / z 228$ being the most abundant member. The wood combustion marker, retene $(m / z 234)$, is present as well. The OC2 fraction shows a different pattern. In addition to the still dominating cellulose breakdown products and anhydrosugar fragments, phenolic compounds appear more prominently in the SPI mass spectrum (e.g., $\mathrm{m} / \mathrm{z}$ $110,124,138,152,164,180,194)$. These compounds were present on the PM-loaded filter either as monomeric products from wood combustion (i.e., from lignin decomposition) or are formed by thermal decomposition of oligomeric plantmaterial combustion products (Subbalakshmi et al., 2000; Mukai and Ambe, 1986). The REMPI spectrum of the OC2 fraction shows a PAH pattern shifted to higher molecular masses $(m / z 228-312)$ with $m / z 252$ being the most abundant member. In addition, smaller breakdown products are appearing (e.g., the homologous series of indanes: $m / z$ 118, $132,146,160)$. Finally, for OC3 the thermal decomposition products dominate: in the SPI mass spectrum the homologue series of the alkenes $(\mathrm{m} / z 42,56,70)$ and dienes/furans $(\mathrm{m} / \mathrm{z}$ $68,82,96,110,124,138)$ become apparently prominent. The REMPI spectrum consolidates this observation: Smaller pyrolysis products such as phenol $(\mathrm{m} / \mathrm{z}, 94)$ and styrene $(\mathrm{m} / \mathrm{z}$ 104) show high abundances while the thermal desorption of PAH is largely completed.

The winter ambient PM sample from Ispra is compared with wood combustion PM emission samples. The two wood burning marker fragments $(\mathrm{m} / \mathrm{z} 60$ and 73 ) and the additional found two markers $(\mathrm{m} / \mathrm{z}, 70$ and 98$)$ can also be seen in the winter sample, indicating a strong wood burning influence.

Besides these four characteristic masses, the same furan and guaiacol derivatives identified in the wood combustion sample can also be found in the winter sample from Ispra (highlighted in Fig. 5 with circles). The similarities between the wood combustion and the ambient winter sample are also striking in the OC3 fraction for the SPI-TOFMS measurements. The same breakdown products for the ambient winter and the wood combustion PM samples can be found, which yields almost the same molecular pattern for the OC3 step. This suggests that the same wood combustion indication parent structures are dominating the organic carbon fraction on the filter in both cases. In addition, the pattern of the nonalkylated PAH which are more pronounced in the results from the ambient winter sample (highlighted with triangles in Fig. 5) resemble EC / OC-PI-TOFMS data from gasoline car emission PM (see Supplement Fig. S4). This indicates an additional transport/vehicle-related emission contribution

In conclusion the EC / OC-PI-TOFMS analysis indicates a strong influence of wood combustion on the winter ambient sample from Italy. This is not surprising, because the sampling station is located in a rural area, which is usually earmarked for residential heating in winter time. The strong influence of wood burning on these samples has also been confirmed by the analysis of Gilardoni et al., 2011, who found biomass burning for residential heating to be the main fraction of the anthropogenic aerosol carbon at this location.

Both, the ambient sample taken in winter and in summer, show high OC contents, 74 and $85 \%$, respectively (Fig. 4). The OC part for the summer is higher indeed, as expected, but the high OC content of the winter sample was surprising. This can be explained by the high influence of wood burning with its high OC values on the winter sample. Due to the high input of residential heating to the OC part of the winter sample, no distinction between summer and winter can be carried out by the OC / EC ratios alone. In this case the coupling to the PI-TOFMS system proves to be helpful.

In summer time the organic aerosol composition differs largely from those in winter. The EC / OC-PI-TOFMS data from an ambient summer PM sample taken at the same location are shown in Fig. 6 (left) and in the Supplement (Fig. S8). No wood combustion markers $(m / z$ 60, 70, 73 and 98$)$ are detectable in the summer sample. Furthermore, no guaiacol or its derivatives $(m / z 124,138,150,152$, 164) can be found neither in the OC1 nor in the OC2 step. The $m / z 98$ signal is only observed at OC2 and thus is not due to wood combustion precursors.

Besides the lack of wood combustion as a source for organic aerosol, no signs of traffic exhaust were found in the summer sample; almost no aromatics were detected at all. A high number of carbonyls, alkenes, and some furan derivatives are present. There are high signals for acetaldehyde $(\mathrm{m} / \mathrm{z} 44)$, acetone/propanal $(\mathrm{m} / \mathrm{z} 58)$, and furan derivatives such as methylfurane $(\mathrm{m} / z \mathrm{82})$.

The lack of both, wood combustion and traffic markers in the summer sample, leads to the question of which source is mainly responsible for the aerosol formation in summer. One possibility is the formation of SOA from VOCs as precursors from biogenic or anthropogenic sources, since in summer the photochemical activity is enhanced and the emission of VOCs, especially biogenic ones such as terpenes, is increased. The high amounts of oxygen-containing species found in the ambient summer sample suggest this assumption.

For validation purposes one sample from the chamber experiments with $\beta$-pinene as precursor is compared to the ambient summer sample. Its respective mass spectra are shown in Fig. 6 on the right side. Both samples yield no detectable aromatic compounds in the first OC step. In the other OC 

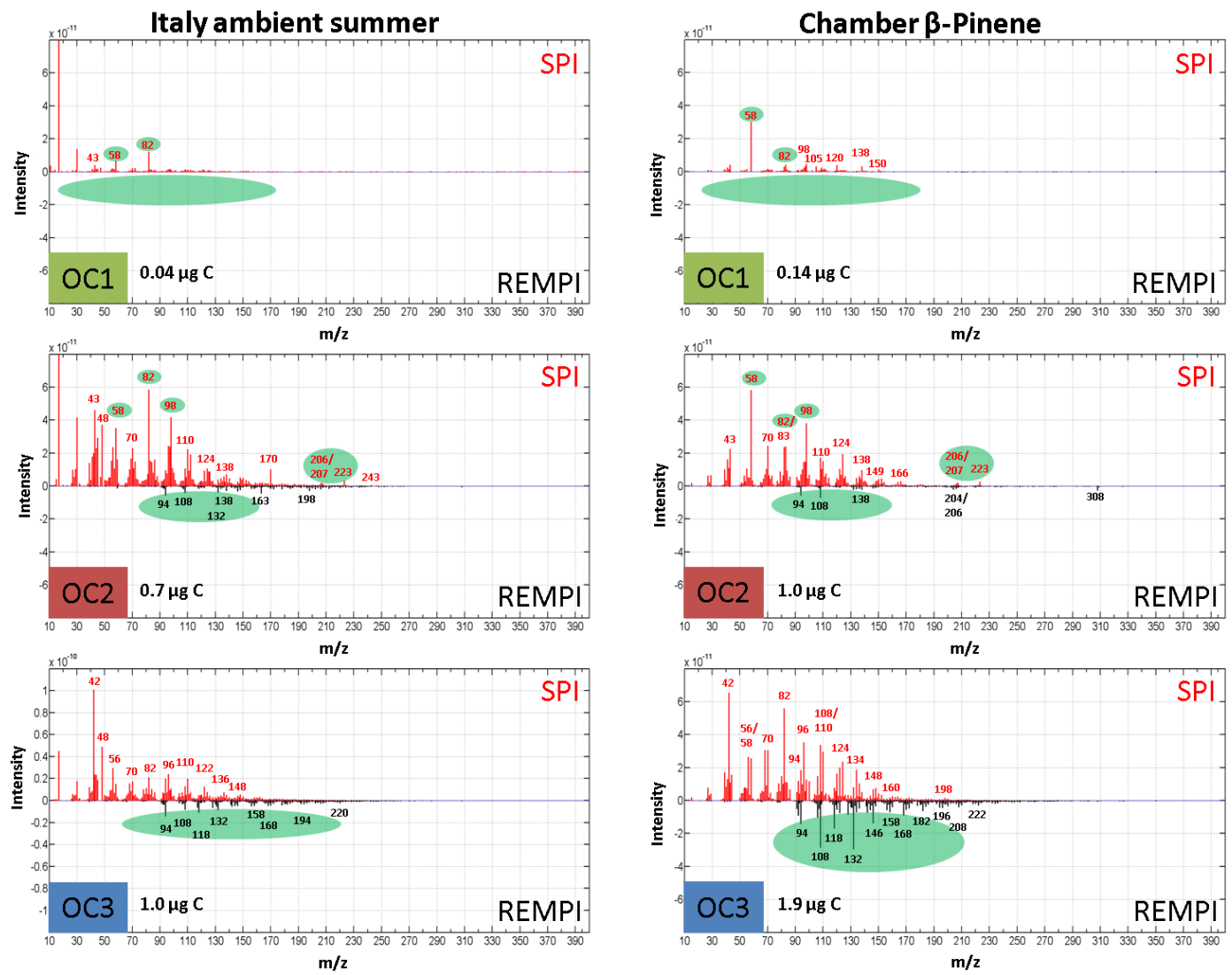

Figure 6. Comparison of the EC / OC PI-TOFMS data (SPI, red/positive and REMPI, black/negative) of the ambient summer PM sample from Ispra and the smog chamber PM sample of a $\beta$-pinene ozonolysis experiment. The averaged mass spectra for OC1, OC2 and OC 3 are shown.

steps, the amount of aromatics is also very low in both cases; however, the patterns are quite similar: $m / z$ 94, 108, $118,132,146,158,182$ are present in the REMPI spectrum. The $\mathrm{m} / \mathrm{z}$ ratios of 94 and 108 could be assigned to phenol and cresols, respectively. Experimental experience with the ionization technique showed that the two aromatics, phenol and cresol, exhibit higher signals with REMPI than with SPI under the same conditions. As a consequence, the higher signal for the two $\mathrm{m} / \mathrm{z}$ ratios 94 and 108 measured with SPI in the OC3 step of both samples can be explained by additional compounds contributing to the signals. Vinylfuran or methylpyrazine for $m / z 94$ and benzyl alcohol or dimethylpyrazine for $m / z 108$ can be assumed. Methylstyrene or benzofuran could be the cause for the signal at $m / z 118$ and ethylstyrene or methylbenzofuran for $m / z 132$. The latter ones are more likely because no styrene $(\mathrm{m} / \mathrm{z}$ 104 ) is present; $\mathrm{m} / \mathrm{z} 146,158$, and 182 could be, among others, methylindanone, methyl naphthol and benzophenone, respectively. Further similarities can be found in the SPI spectra of the first two OC steps. The dominant signals are at $\mathrm{m} / \mathrm{z}$ 58,82 and 98 , respectively. The $m / z 58$ and 82 are neither present in the winter sample from the same location nor in any other emission source sample (wood combustion, gaso- line and diesel emission, the vehicle emission samples that can be found in the Supplement) and seem to be therefore characteristic for secondary biogenic aerosols. The $m / z$ ratio of 58 can be assigned to several compounds, among others acetone, propanal, glyoxal, but acetone and glyoxal have already been reported to form in chamber experiments with monoterpenes (Larsen et al., 2001; Jaoui et al., 2008). The $\mathrm{m} / \mathrm{z}$ of 82 could be assigned to methylpyrazole or methylfuran, whereby the latter one has already been found in chamber experiments, but with isoprene as a precursor (Surratt et al., 2006). Both samples also show high amounts of the $\mathrm{m} / \mathrm{z}$ ratios 122 and 136, which could be assigned to benzoic acid/hydroxybenzaldehyde and phenylacetic acid, respectively. No typical $\beta$-pinene oxidation products, as they have been found by other working groups (Larsen et al., 2001; Glasius et al., 2000; Jaoui and Kamens, 2003), have been detected, such as pinic acid $(m / z 186)$, pinalic acid $(m / z$ 170), 10-hydroxypinonic acid $(m / z 200)$, or hydroxypinonaldehyde $(m / z$ 184). This could be due to the fact that acids decarboxylize at high temperatures or yields of these products are beneath the detection limit. Despite the lack of typical $\beta$-pinene SOA markers the similarities between the chamber sample and the Italy summer sample are strik- 

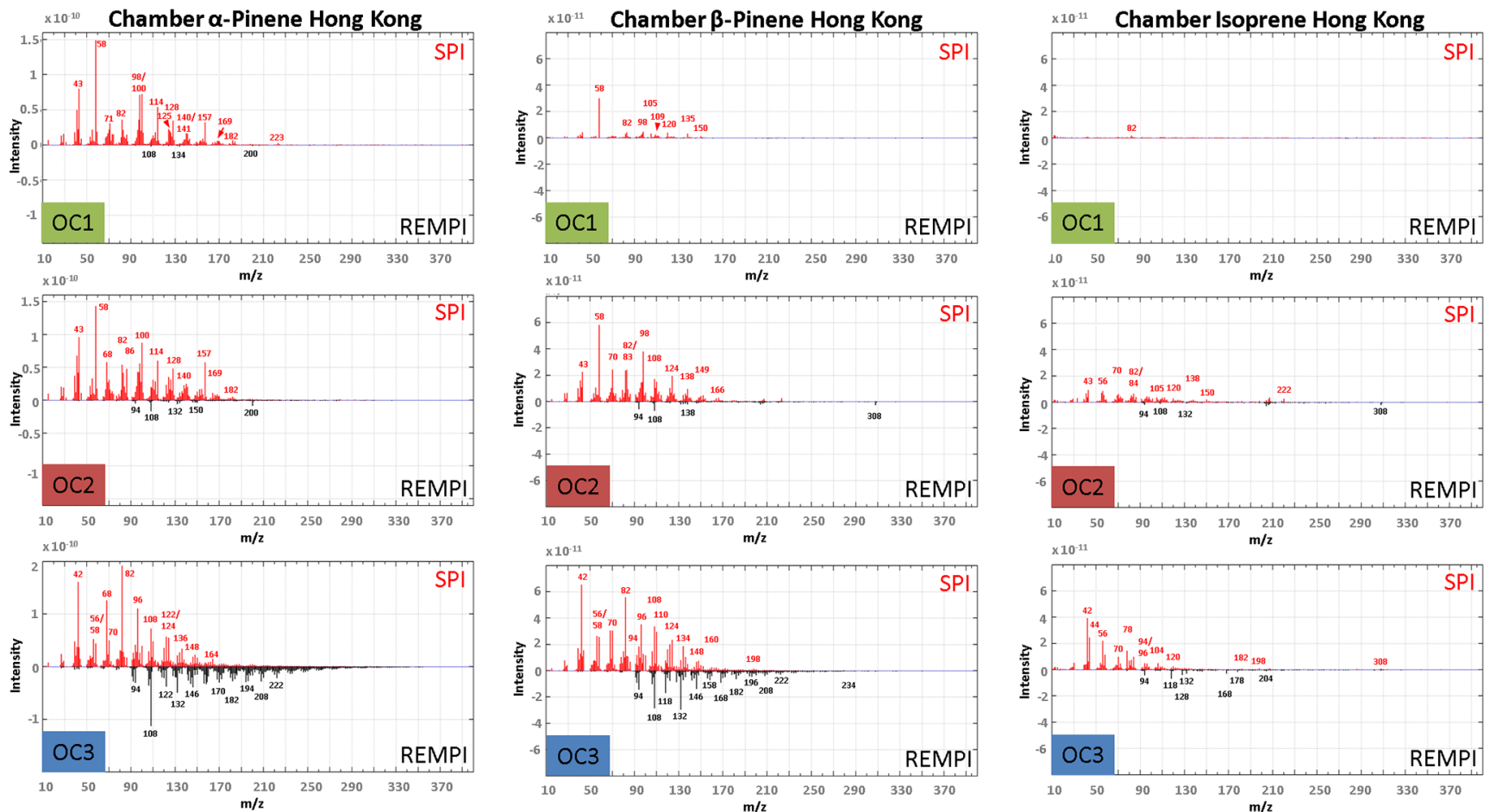

Figure 7. Comparison of the EC / OC-PI-TOFMS data (SPI - red/positive and REMPI - black/negative) of smog chamber PM samples of the $\alpha$-pinene, $\beta$-pinene, and iosoprene ozonolysis experiments. The averaged mass spectra for OC1, OC2, and OC 3 are shown.

ing; thus, it is very likely that the main contributor to the organic carbonaceous aerosol phase in Ispra in summer are compounds of secondary origin. This is in good agreement with Gilardoni et al., 2011, who stated, that the sampling site near Ispra behaves in winter like a rural and in summer like an urban site, and that SOA represents $85 \%$ and especially biogenic SOA $56 \%$ of the organic mass during summer.

\subsection{Chamber generated secondary aerosol filter samples}

Besides $\beta$-pinene other precursors such as $\alpha$-pinene and isoprene have been investigated for the chamber experiments. A comparison of the three experiments is given in Fig. 7.

All chamber experiments show no or only a very small EC fraction, so all OC fractions account to almost $100 \%$ of aerosol carbon. $\alpha$-Pinene yields on the one hand a lot more gaseous compounds than $\beta$-pinene which, on the other hand, yields higher amounts of particulate species and therefore SOA, than isoprene. The spectra of the experiments with all three precursors have a strong aliphatic signature with much lower aromatic contribution.

$\alpha$-pinene as a precursor shows high signals at $\mathrm{m} / z$ ratios of 58,82 , and 98 . These are the same masses that seemed to be characteristic for the $\beta$-pinene and the ambient summer sample. In addition to the $\beta$-pinene sample, signals at $m / z 68$ (furan and isoprene) and 71 can be found in the first two OC steps. Furthermore, oxygen-containing compounds are present: $\mathrm{m} / \mathrm{z} 86$ (methylbutanal), $\mathrm{m} / \mathrm{z} 100$ (dihydromethylfuranone), $m / z 114$ (ethylfuranone), and $\mathrm{m} / z 128$ (nonane, heptadione, acetyl-dihydro-furanone). A lot of odd masses can be seen in the spectrum of the OC1 and OC2 step: $m / z 125,141,157$, and 169 , in which only the $m / z$ ratio 169 was already found and identified as nitroguaiacol or hydroxy-nitrobenzyl alcohol (from toluene; Jaoui et al., 2008). Except the $m / z 140$ (2,2-dimethyl-cyclobutyl1,3-diethanal or trimethyl-cyclohex-2-en-1-ol), which was obtained from chamber experiments with $\alpha$ - and $\beta$-pinene and $\alpha$-pinene alone (Jaoui and Kamens, 2003), no typical $\alpha$-pinene chamber reaction products (Larsen et al., 2001; Koch et al., 2000; Glasius et al., 2000) were identified. There are signals at $m / z 154$ (norpinonaldehyde), 168 (pinonaldehyde), 170 (pinalic acid or norpinonic acid), 172 (norpinic acid), and 184 (pinonic acid), but their intensities are rather low. Besides the $m / z$ ratio 200 no significant difference can be observed between the aromatic product patterns of both terpenes.

The other precursor isoprene yields significantly smaller amounts of products than the two terpenes. The contribution of isoprene to the formation of SOA in the atmosphere is a controversial topic. On the one hand the formation of SOA from isoprene as a precursor is believed to be insignificant (Kanakidou et al., 2005; Pandis et al., 1991, 1992) and less than from other precursors; on the other hand, isoprene accounts for $44 \%$ of the biogenic VOC emission (Bal- 
tensperger et al., 2005) and it is one of the main precursors in ambient air (Guenther et al., 1994). On the other hand, isoprene is believed to contribute a lot to the aerosol mass by oxidation with $\mathrm{OH}$ radicals to form 2-methylthreitol and 2-methylerythritol and by forming oligomeric structures, such as HULIS, but only under acidic conditions (Surratt et al., 2006; Claeys et al., 2004). The first statement can be supported by this study, and only a small variety and low amounts of SOA products can be seen in the spectra of isoprene (see Figs. 9 or S13). In the OC1 phase, except for the $\mathrm{m} / \mathrm{z} 82$ no substances were detectable. The second statement on the contrary cannot be supported, because a formation and therefore presence of oligomeric structures would lead to a high amount of thermal breakdown products in the OC3 phase, which was not the case. One explanation for the lack of oligomeric structures could be that the reaction conditions of the chamber experiment were not acidic. The fact that only small amounts of SOA products were found does not mean that isoprene does not contribute significantly to the ambient aerosol mass, because of its high abundance in the atmosphere. Isoprene shows no high signals at the $m / z$ ratios of 58,82 , and 98 and $\mathrm{m} / z$ of 44 (acetaldehyde) in the OC3 phase compared to the terpenes. This leads to the assumption that the dominant signals in the terpene experiments $(\mathrm{m} / z 58$, $82,98)$ are only characteristic for terpenes and not for other precursors.

\section{Conclusions}

The carbon analyzer enables the stepwise heating of filter samples (off-line) and the determination of bulk parameters (OC, EC, TC). The PI-TOFMS system allows for the fast analysis of the evolving gaseous species. In combination they provide an expanded technique for aerosol analysis giving deeper insight into the chemical signature. A filter-based PM analysis system has the advantage that filters from measurement networks around the world (e.g., from monitoring programs such as IMPROVE; Chen et al., 2012; Pitchford and Joseph, 1990) and specific experiments (e.g., smog chamber measurements) can be obtained and analyzed in the laboratory. The combination of PI-MS with EC / OC analysis is beneficial, as the data offer a more detailed insight into the molecular composition of organic aerosol fractions obtained by the carbon analyzer. If a source classification via $\mathrm{OC} / \mathrm{EC}$ ratios is difficult, the mass spectrometric data can help with characteristic markers (in this study the distinction between summer and winter sample from Ispra). In addition data can be readily aligned in existing measurements series. It was shown that the technique is suitable to analyze samples from various origins, emission samples, ambient samples as well as chamber experiment samples from different precursors. Therefore, it allows for differentiation of primary and secondary aerosol components and oligomeric structures. Of course there are limitations. In the carbon measurements they lie in the distinction between OC and EC. It is highly de- pendable on the laser correction method and the utilized carrier gas system as well as the temperature protocol. Due to the unit mass resolution of the mass spectrometer, an assignment of compounds to the measured $\mathrm{m} / \mathrm{z}$ ratios can only be done taking into account the unique properties of the ionization technique (selectivity, ionization efficiency) and literature data as well as own experimental experience from previous studies, the latter also comprising chromatographic analyses to confirm assignments .

In the investigated PM samples, the fragments at $m / z 60$ and 73, which are known wood combustion marker fragments in AMS studies, were confirmed. They were also found in the ambient sample taken in Ispra in winter confirming the strong influence of residential heating on the aerosol mass.

High signals of the $m / z$ ratios 58 and 82 were only present in the samples from the chamber experiments conducted with $\alpha$ - and $\beta$-pinene as a precursor and also in the ambient sample taken in summer in Ispra. Their absence in other emission samples and the ambient sample taken in winter from the same location leads to the assumption that these two masses could be used as a marker for secondary biogenic aerosols. The statement should be confirmed by carrying out further analysis with additional samples.

The experiments with $\alpha$-pinene carried out in different chambers revealed similar products. Thus, the analytical technique proved to be reliable and reproducible. No significant contribution of isoprene to the formation of SOA could be observed and no enhanced formation of oligomeric structures, as stated in the literature, could be detected with the analytical technique and the conditions used in the chamber experiments. It would be useful to conduct additional analysis with higher mass resolution to get more information about the structures behind these masses and to confirm the proposed compounds and back up the hypotheses.

\section{The Supplement related to this article is available online at doi:10.5194/amt-8-3337-2015-supplement.}

Acknowledgements. This work was financed by the Deutsche Forschungsgemeinschaft (DFG, code number ZI764_1-2). The authors thank Kochy Fung for his ongoing help and ideas for the coupling. The wood combustion samples were provided by the Helmholtz Zentrum München, where special thanks go to Jürgen Orasche. For the assistance with the ambient samples, we would like to thank Kevin Douglas from the European Commission Joint Research Centre (JRC) in Ispra, Italy. Very special thanks go to Simone Krüger for assistance with the instrument and the measurements.

The health effects of anthropogenic combustion aerosols are currently addressed in the framework of the Helmholtz Virtual Institute of Complex Molecular Systems in Environmental Health (HICE) - Aerosol and Health (www.hice-vi.eu). In particular the 
organic molecular composition is of interest in this context. The developed instrument is currently applied in the HICE research projects.

Edited by: W. Maenhaut

\section{References}

Adam, T. and Zimmermann, R.: Determination of single photon ionization cross sections for quantitative analysis of complex organic mixtures, Anal. Bioanal. Chem., 389, 1941-1951, 2007.

Aiken, A. C., Salcedo, D., Cubison, M. J., Huffman, J. A., DeCarlo, P. F., Ulbrich, I. M., Docherty, K. S., Sueper, D., Kimmel, J. R., Worsnop, D. R., Trimborn, A., Northway, M., Stone, E. A., Schauer, J. J., Volkamer, R. M., Fortner, E., de Foy, B., Wang, J., Laskin, A., Shutthanandan, V., Zheng, J., Zhang, R., Gaffney, J., Marley, N. A., Paredes-Miranda, G., Arnott, W. P., Molina, L. T., Sosa, G., and Jimenez, J. L.: Mexico City aerosol analysis during MILAGRO using high resolution aerosol mass spectrometry at the urban supersite (T0) - Part 1: Fine particle composition and organic source apportionment, Atmos. Chem. Phys., 9, 6633-6653, doi:10.5194/acp-9-6633-2009, 2009.

Alfarra, M. R., Prevot, A. S. H., Szidat, S., Sandradewi, J., Weimer, S., Lanz, V. A., Schreiber, D., Mohr, M., and Baltensperger, U.: Identification of the mass spectral signature of organic aerosols from wood burning emissions, Environ. Sci. Technol., 41, 5770-5777, 2007.

Andreae, M. O. and Gelencsér, A.: Black carbon or brown carbon? The nature of light-absorbing carbonaceous aerosols, Atmos. Chem. Phys., 6, 3131-3148, doi:10.5194/acp-6-3131-2006, 2006.

Andreae, M. O., Rosenfeld, D., Artaxo, P., Costa, A. A., Frank, G. P., Longo, K. M., and Silva-Dias, M. A. F.: Smoking rain clouds over the amazon, Science, 303, 1337-1342, 2004.

Atkinson, R. and Aschmann, S. M.: Atmospheric chemistry of the monoterpene reaction products nopinone, camphenilone, and 4-acetyl-1-methylcyclohexene, J. Atmos. Chem., 16, 337-348, 1993.

Aymoz, G., Jaffrezo, J. L., Chapuis, D., Cozic, J., and Maenhaut, W.: Seasonal variation of $\mathrm{PM}_{10}$ main constituents in two valleys of the French Alps. I: EC / OC fractions, Atmos. Chem. Phys., 7, 661-675, doi:10.5194/acp-7-661-2007, 2007.

Baltensperger, U., Kalberer, M., Dommen, J., Paulsen, D., Alfarra, M. R., Coe, H., Fisseha, R., Gascho, A., Gysel, M., Nyeki, S., Sax, M., Steinbacher, M., Prevot, A. S. H., Sjögren, S., Weingartner, E., and Zenobi, R.: Secondary organic aerosols from anthropogenic and biogenic precursors, Faraday Discuss., 130, 265-278, 2005.

Bente, M., Sklorz, M., Streibel, T., and Zimmermann, R.: Online laser desorption-multiphoton postionization mass spectrometry of individual aerosol particles: molecular source indicators for particles emitted from different traffic-related and wood combustion sources, Anal. Chem., 80, 8991-9004, 2008.

Boesl, U.: Laser mass spectrometry for environmental and industrial chemical trace analysis, J. Mass Spectrom., 35, 289-304, 2000.

Butcher, D. J., Goeringer, D. E., and Hurst, G. B.: Real-time determination of aromatics in automobile exhaust by single-photon ionization ion trap mass spectrometry, Anal. Chem., 71, 489496, 1999.

Cass, G. R.: Organic molecular tracers for particulate air pollution sources, Trac-Trend. Anal. Chem., 17, 356-366, 1998.

Charlson, R. J., Schwartz, S. E., Hales, J. M., Cess, R. D., Coakley Jr., J. A., Hansen, J. E., and Hofmann, D. J.: Climate forcing by anthropogenic aerosols, Science, 255, 423-430, 1992.

Chen, L.-W. A., Watson, J. G., Chow, J. C., Green, M. C., Inouye, D., and Dick, K.: Wintertime particulate pollution episodes in an urban valley of the Western US: a case study, Atmos. Chem. Phys., 12, 10051-10064, doi:10.5194/acp-12-10051-2012, 2012.

Chow, J. C., Watson, J. G., Pritchett, L. C., Pierson, W. R., Frazier, C. A., and Purcell, R. G.: The dri thermal/optical reflectance carbon analysis system: description, evaluation and applications in US Air quality studies, Atmos. Environ. A-Gen., 27, 11851201, 1993.

Chow, J. C., Watson, J. G., Crow, D., Lowenthal, D. H., and Merrifield, T.: Comparison of IMPROVE and NIOSH carbon measurements, Aerosol Sci. Tech., 34, 23-34, 2001.

Chow, J. C., Watson, J. G., Lowenthal, D. H., Chen, L.-W. A., and Magliano, K. L.: Particulate carbon measurements in California's San Joaquin Valley, Chemosphere, 62, 337-348, 2006.

Chow, J. C., Watson, J. G., Lowenthal, D. H., Chen, L. W. A., Zielinska, B., Mazzoleni, L. R., and Magliano, K. L.: Evaluation of organic markers for chemical mass balance source apportionment at the Fresno Supersite, Atmos. Chem. Phys., 7, 17411754, doi:10.5194/acp-7-1741-2007, 2007a.

Chow, J. C., Watson, J. G., Chen, L. W. A., Chang, M. C. O., Robinson, N. F., Trimble, D., and Kohl, S.: The IMPROVE_A temperature protocol for thermal/optical carbon analysis: maintaining consistency with a long-term database, J. Air Waste Manage., 57, 1014-1023, 2007b.

Chow, J. C., Watson, J. G., Lowenthal, D. H., Chen, L.-W. A., and Motallebi, N.: $\mathrm{PM}_{2.5}$ source profiles for black and organic carbon emission inventories, Atmos. Environ., 45, 5407-5414, 2011.

Claeys, M., Graham, B., Vas, G., Wang, W., Vermeylen, R., Pashynska, V., Cafmeyer, J., Guyon, P., Andreae, M. O., Artaxo, P., and Maenhaut, W.: Formation of secondary organic aerosols through photooxidation of isoprene, Science, 303, 1173-1176, 2004.

de Gouw, J. A., Middlebrook, A. M., Warneke, C., Goldan, P. D., Kuster, W. C., Roberts, J. M., Fehsenfeld, F. C., Worsnop, D. R., Canagaratna, M. R., Pszenny, A. A. P., Keene, W. C., Marchewka, M., Bertman, S. B., and Bates, T. S.: Budget of organic carbon in a polluted atmosphere: results from the New England Air Quality Study in 2002, J. Geophys. Res.-Atmos., 110, 1-22, 2005.

Dorfner, R., Ferge, T., Yeretzian, C., Kettrup, A., and Zimmermann, R.: Laser mass spectrometry as on-line sensor for industrial process analysis: process control of coffee roasting, Anal. Chem., 76, 1386-1402, 2004.

Elsasser, M., Crippa, M., Orasche, J., DeCarlo, P. F., Oster, M., Pitz, M., Cyrys, J., Gustafson, T. L., Pettersson, J. B. C., Schnelle-Kreis, J., Prévôt, A. S. H., and Zimmermann, R.: Organic molecular markers and signature from wood combustion particles in winter ambient aerosols: aerosol mass spectrometer (AMS) and high time-resolved GC-MS measurements in Augsburg, Germany, Atmos. Chem. Phys., 12, 6113-6128, doi:10.5194/acp-12-6113-2012, 2012. 
Eschner, M. S. and Zimmermann, R.: Determination of photoionization cross-sections of different organic molecules using gas chromatography coupled to single-photon ionization (SPI) timeof-flight mass spectrometry (TOF-MS) with an electron-beampumped rare gas excimer light source (EBEL): influence of molecular structure and analytical implications, Appl. Spectrosc., 65, 806-816, 2011.

Faix, O., Meier, D., and Grobe, I.: Studies on isolated lignins and lignins in woody materials by pyrolysis-gas chromatographymass spectrometry and off-line pyrolysis-gas chromatography with flame ionization detection, J. Anal. Appl. Pyrol., 11, 403416, doi:10.1016/0165-2370(87)85044-1, 1987.

Fang, W., Gong, L., Shan, X., Liu, F., Wang, Z., and Sheng, L.: Thermal desorption/tunable vacuum-ultraviolet time-of-flight photoionization aerosol mass spectrometry for investigating secondary organic aerosols in chamber experiments, Anal. Chem., 83, 9024-9032, 2011.

Ferge, T., Mühlberger, F., and Zimmermann, R.: Application of infrared laser desorption vacuum-UV single-photon ionization mass spectrometry for analysis of organic compounds from particulate matter filter samples, Anal. Chem., 77, 4528-4538, 2005a.

Ferge, T., Maguhn, J., Hafner, K., Mühlberger, F., Davidovic, M., Warnecke, R., and Zimmermann, R.: On-line analysis of gasphase composition in the combustion chamber and particle emission characteristics during combustion of wood and waste in a small batch reactor, Environ. Sci. Technol., 39, 1393-1402, 2005b.

Ferge, T., Karg, E., Schröppel, A., Coffee, K. R., Tobias, H. J., Frank, M., Gard, E. E., and Zimmermann, R.: Fast determination of the relative elemental and organic carbon content of aerosol samples by on-line single-particle aerosol time-of-flight mass spectrometry, Environ. Sci. Technol., 40, 3327-3335, 2006.

Fine, P. M., Cass, G. R., and Simoneit, B. R. T.: Chemical characterization of fine particle emissions from the fireplace combustion of woods grown in the Southern United States, Environ. Sci. Technol., 36, 1442-1451, 2002.

Fine, P. M., Cass, G. R., and Simoneit, B. R. T.: Chemical characterization of fine particle emissions from the wood stove combustion of prevalent united states tree species, Environ. Eng. Sci., 21, 705-721, 2004.

Gao, S., Ng, N. L., Keywood, M., Varutbangkul, V., Bahreini, R., Nenes, A., He, J., Yoo, K. Y., Beauchamp, J. L., Hodyss, R. P., Flagan, R. C., and Seinfeld, J. H.: Particle phase acidity and oligomer formation in secondary organic aerosol, Environ. Sci. Technol., 38, 6582-6589, 2004.

Gard, E., Mayer, J. E., Morrical, B. D., Dienes, T., Fergenson, D. P., and Prather, K. A.: Real-time analysis of individual atmospheric aerosol particles: design and performance of a portable ATOFMS, Anal. Chem., 69, 4083-4091, 1997.

Gelencsér, A.: Carbonaceous Aerosol, Springer, Dordrecht, the Netherlands, chap. IX, 350 pp., 2004.

Gilardoni, S., Vignati, E., Cavalli, F., Putaud, J. P., Larsen, B. R., Karl, M., Stenström, K., Genberg, J., Henne, S., and Dentener, F.: Better constraints on sources of carbonaceous aerosols using a combined ${ }^{14} \mathrm{C}$ - macro tracer analysis in a European rural background site, Atmos. Chem. Phys., 11, 5685-5700, doi:10.5194/acp-11-5685-2011, 2011.
Glasius, M., Lahaniati, M., Calogirou, A., Di Bella, D., Jensen, N. R., Hjorth, J., Kotzias, D., and Larsen, B. R.: Carboxylic acids in secondary aerosols from oxidation of cyclic monoterpenes by ozone, Environ. Sci. Technol., 34, 1001-1010, 2000.

Graber, E. R. and Rudich, Y.: Atmospheric HULIS: How humic-like are they? A comprehensive and critical review, Atmos. Chem. Phys., 6, 729-753, doi:10.5194/acp-6-729-2006, 2006.

Grabowsky, J., Streibel, T., Sklorz, M., Chow, J. C., Watson, J. G., Mamakos, A., and Zimmermann, R.: Hyphenation of a carbon analyzer to photo-ionization mass spectrometry to unravel the organic composition of particulate matter on a molecular level, Anal. Bioanal. Chem., 401, 3153-3164, 2011.

Guenther, A., Zimmerman, P., and Wildermuth, M.: Natural volatile organic compound emission rate estimates for US woodland landscapes, Atmos. Environ., 28, 1197-1210, 1994.

Gullett, B., Touati, A., and Oudejans, L.: Use of REMPI-TOFMS for real-time measurement of trace aromatics during operation of aircraft ground equipment, Atmos. Environ., 42, 2117-2128, 2008.

Hallquist, M., Wenger, J. C., Baltensperger, U., Rudich, Y., Simpson, D., Claeys, M., Dommen, J., Donahue, N. M., George, C., Goldstein, A. H., Hamilton, J. F., Herrmann, H., Hoffmann, T., Iinuma, Y., Jang, M., Jenkin, M. E., Jimenez, J. L., KiendlerScharr, A., Maenhaut, W., McFiggans, G., Mentel, T. F., Monod, A., Prévôt, A. S. H., Seinfeld, J. H., Surratt, J. D., Szmigielski, R., and Wildt, J.: The formation, properties and impact of secondary organic aerosol: current and emerging issues, Atmos. Chem. Phys., 9, 5155-5236, doi:10.5194/acp-9-51552009, 2009.

Han, Y., Chen, A., Cao, J., Fung, K., Ho, F., Yan, B., Zhan, C., Liu, S., Wei, C., and An, Z.: Thermal/optical methods for elemental carbon quantification in soils and urban dusts: equivalence of different analysis protocols, PLoS ONE, 8, 2013.

Hennigan, C. J., Miracolo, M. A., Engelhart, G. J., May, A. A., Presto, A. A., Lee, T., Sullivan, A. P., McMeeking, G. R., Coe, H., Wold, C. E., Hao, W.-M., Gilman, J. B., Kuster, W. C., de Gouw, J., Schichtel, B. A., Collett Jr., J. L., Kreidenweis, S. M., and Robinson, A. L.: Chemical and physical transformations of organic aerosol from the photo-oxidation of open biomass burning emissions in an environmental chamber, Atmos. Chem. Phys., 11, 7669-7686, doi:10.5194/acp-11-76692011, 2011.

Hertz, R., Streibel, T., Liu, C., McAdam, K., and Zimmermann, R.: Microprobe sampling-Photo ionization-time-of-flight mass spectrometry for in situ chemical analysis of pyrolysis and combustion gases: examination of the thermo-chemical processes within a burning cigarette, Anal. Chim. Acta, 714, 104-113, 2012.

Jacobson, M. C., Hansson, H. C., Noone, K. J., and Charlson, R. J.: Organic atmospheric aerosols: review and state of the science, Rev. Geophys., 38, 267-294, 2000.

Jang, M., Carroll, B., Chandramouli, B., and Kamens, R. M.: Particle growth by acid-catalyzed heterogeneous reactions of organic carbonyls on preexisting aerosols, Environ. Sci. Technol., 37, 3828-3837, 2003.

Jaoui, M. and Kamens, R. M.: Gaseous and particulate oxidation products analysis of a mixture of a-pinene + b-pinene/O3/air in the absence of light and a-pinene $+\mathrm{b}$-pinene/NOx/air in the presence of natural sunlight, J. Atmos. Chem., 44, 259-297, 2003. 
Jaoui, M., Edney, E. O., Kleindienst, T. E., Lewandowski, M., Offenberg, J. H., Surratt, J. D., and Seinfeld, J. H.: Formation of secondary organic aerosol from irradiated $\alpha$-pinene/toluene/NOx mixtures and the effect of isoprene and sulfur dioxide, J. Geophys. Res.-Atmos., 113, D09303, doi:10.1029/2007JD009426, 2008.

Kanakidou, M., Seinfeld, J. H., Pandis, S. N., Barnes, I., Dentener, F. J., Facchini, M. C., Van Dingenen, R., Ervens, B., Nenes, A., Nielsen, C. J., Swietlicki, E., Putaud, J. P., Balkanski, Y., Fuzzi, S., Horth, J., Moortgat, G. K., Winterhalter, R., Myhre, C. E. L., Tsigaridis, K., Vignati, E., Stephanou, E. G., and Wilson, J.: Organic aerosol and global climate modelling: a review, Atmos. Chem. Phys., 5, 1053-1123, doi:10.5194/acp5-1053-2005, 2005.

Koch, S., Winterhalter, R., Uherek, E., Kolloff, A., Neeb, P., and Moortgat, G. K.: Formation of new particles in the gas-phase ozonolysis of monoterpenes, Atmos. Environ., 34, 4031-4042, 2000.

Kohse-Höinghaus, K. and Brockhinke, A.: Experimental and numerical methods for studying the flame structure, Combust. Explo. Shock+, 45, 349-364, 2009.

Larsen, B. R., Di Bella, D., Glasius, M., Winterhalter, R., Jensen, N. R., and Hjorth, J.: Gas-phase $\mathrm{OH}$ oxidation of monoterpenes: gaseous and particulate products, J. Atmos. Chem., 38, 231-276, 2001.

Lee, T., Sullivan, A. P., MacK, L., Jimenez, J. L., Kreidenweis, S. M., Onasch, T. B., Worsnop, D. R., Malm, W., Wold, C. E., Hao, W. M., and Collett Jr, J. L.: Chemical smoke marker emissions during flaming and smoldering phases of laboratory open burning of wildland fuels, Aerosol Sci. Tech., 44, i-v, 2010.

Lim, H. J. and Turpin, B. J.: Origins of primary and secondary organic aerosol in Atlanta: results of time-resolved measurements during the Atlanta Supersite Experiment, Environ. Sci. Technol., 36, 4489-4496, 2002.

Maker, P. D. and Terhune, R. W.: Study of optical effects due to an induced polarization third order in the electric field strength, Phys. Rev., 137, 801-818, 1965.

McDonald, J. D., Zielinska, B., Fujita, E. M., Sagebiel, J. C., Chow, J. C., and Watson, J. G.: Fine particle and gaseous emission rates from residential wood combustion, Environ. Sci. Technol., 34, 2080-2091, 2000.

Mitschke, S., Adam, T., Streibel, T., Baker, R. R., and Zimmermann, R.: Application of time-of-flight mass spectrometry with laser-based photoionization methods for time-resolved on-line analysis of mainstream cigarette smoke, Anal. Chem., 77, 22882296, 2005.

Moosmüller, H., Chakrabarty, R. K., and Arnott, W. P.: Aerosol light absorption and its measurement: a review, J. Quant. Spectrosc. Ra., 110, 844-878, 2009.

Mühlberger, F., Zimmermann, R., and Kettrup, A.: A mobile mass spectrometer for comprehensive on-line analysis of trace and bulk components of complex gas mixtures: parallel application of the laser-based ionization methods VUV single-photon ionization, resonant multiphoton ionization, and laser-induced electron impact ionization, Anal. Chem., 73, 3590-3604, 2001.

Mukai, H. and Ambe, Y.: Characterization of a humic acid-like brown substance in airborne particulate matter and tentative iden- tification of its origin, Atmos. Environ. A-Gen., 20, 813-819, 1986.

Nel, A.: Air pollution-related illness: effects of particles, Science, 308, 804-806, 2005.

Nolte, C. G., Schauer, J. J., Cass, G. R., and Simoneit, B. R. T.: Highly polar organic compounds present in wood smoke and in the ambient atmosphere, Environ. Sci. Technol., 35, 1912-1919, 2001.

Novakov, T. and Penner, J. E.: Large contribution of organic aerosols to cloud-condensation-nuclei concentrations, Nature, 365, 823-826, 1993.

Oser, H., Copic, K., Coggiola, M. J., Faris, G. W., and Crosley, D. R.: Congener-specific detection of dioxins using jetREMPI, Chemosphere, 43, 469-477, 2001.

Pandis, S. N., Paulson, S. E., Seinfeld, J. H., and Flagan, R. C.: Aerosol formation in the photooxidation of isoprene and $\beta$ pinene, Atmos. Environ. A-Gen., 25, 997-1008, 1991.

Pandis, S. N., Harley, R. A., Cass, G. R., and Seinfeld, J. H.: Secondary organic aerosol formation and transport, Atmos. Environ. A-Gen., 26, 2269-2282, 1992.

Pitchford, M. and Joseph, D.: IMPROVE Progress Report, EPA Office of Air Quality, Office of Air Quality Planning and Standards, U.S. EPA, Research Triangle Park, North Carolina, USA, 1990.

Rogge, W. F., Mazurek, M. A., Hildemann, L. M., Cass, G. R., and Simoneit, B. R. T.: Quantification of urban organic aerosols at a molecular level: identification, abundance and seasonal variation, Atmos. Environ. A-Gen., 27, 1309-1330, 1993.

Rogge, W. F., Hildemann, L. M., Mazurek, M. A., Cass, G. R., and Simoneit, B. R. T.: Sources of fine organic aeresol. 9. Pine, oak, and synthetic log combustion in residential fireplaces, Environ. Sci. Technol., 32, 13-22, 1998.

Samet, J. M., Dominici, F., Curriero, F. C., Coursac, I., and Zeger, S. L.: Fine particulate air pollution and mortality in 20 US cities, 1987-1994, New Engl. J. Med., 343, 1742-1749, 2000.

Samy, S. and Hays, M. D.: Quantitative LC-MS for water-soluble heterocyclic amines in fine aerosols $\left(\mathrm{PM}_{2.5}\right)$ at Duke Forest, USA, Atmos. Environ., 72, 77-80, 2013.

Schauer, J. J. and Cass, G. R.: Source apportionment of wintertime gas-phase and particle-phase air pollutants using organic compounds as tracers, Environ. Sci. Technol., 34, 1821-1832, 2000.

Schauer, J. J., Rogge, W. F., Hildemann, L. M., Mazurek, M. A., Cass, G. R., and Simoneit, B. R. T.: Source apportionment of airborne particulate matter using organic compounds as tracers, Atmos. Environ., 30, 3837-3855, 1996.

Schnelle-Kreis, J., Sklorz, M., Peters, A., Cyrys, J., and Zimmermann, R.: Analysis of particle-associated semi-volatile aromatic and aliphatic hydrocarbons in urban particulate matter on a daily basis, Atmos. Environ., 39, 7702-7714, 2005.

Schnelle-Kreis, J., Sklorz, M., Orasche, J., Stölzel, M., Peters, A., and Zimmermann, R.: Semi volatile organic compounds in ambient $\mathrm{PM}_{2.5}$ seasonal trends and daily resolved source contributions, Environ. Sci. Technol., 41, 3821-3828, 2007.

Schwartz, J., Ballester, F., Saez, M., Pérez-Hoyos, S., Bellido, J., Cambra, K., Arribas, F., Canada, A., Pérez-Boillos, M. J., and Sunyer, J.: The concentration-response relation between air pollution and daily deaths, Environ. Health Persp., 109, 1001-1006, 2001.

Seinfeld, J. H. and Pankow, J. F.: organic atmospheric particulate material, Annu. Rev. Phys. Chem., 54, 121-140, 2003. 
Subbalakshmi, Y., Patti, A. F., Lee, G. S. H., and Hooper, M. A.: Structural characterisation of macromolecular organic material in air particulate matter using Py-GC-MS and solid state 13CNMR, J. Environ. Monitor., 2, 561-565, 2000.

Surratt, J. D., Murphy, S. M., Kroll, J. H., Ng, N. L., Hildebrandt, L., Sorooshian, A., Szmigielski, R., Vermeylen, R., Maenhaut, W., Claeys, M., Flagan, R. C., and Seinfeld, J. H.: Chemical composition of secondary organic aerosol formed from the photooxidation of isoprene, J. Phys. Chem. A, 110, 9665-9690, 2006.

Tobias, H. J. and Ziemann, P. J.: Compound identification in organic aerosols using temperature-programmed thermal desorption particle beam mass spectrometry, Anal. Chem., 71, 3428$3435,1999$.

Tolocka, M. P., Jang, M., Ginter, J. M., Cox, F. J., Kamens, R. M., and Johnston, M. V.: Formation of oligomers in secondary organic aerosol, Environ. Sci. Technol., 38, 1428-1434, 2004.

Vicente, A., Alves, C., Monteiro, C., Nunes, T., Mirante, F., Cerqueira, M., Calvo, A., and Pio, C.: Organic speciation of aerosols from wildfires in central Portugal during summer 2009, Atmos. Environ., 57, 186-196, 2012.

Vidal, C. R.: Four-wave frequency mixing in gases, in: Tunable Lasers, edited by: Mollenauer, L. F. and White, J. C., Springer Verlag, Berlin, Germany, 56-113, 1987.

Watson, J. G., Chow, J. C., Lowenthal, D. H., Pritchett, L. C., Frazier, C. A., Neuroth, G. R., and Robbins, R.: Differences in the carbon composition of source profiles for diesel- and gasolinepowered vehicles, Atmos. Environ., 28, 2493-2505, 1994.
Watson, J. G., Chow, J. C., and Chen, L.-W. A.: Summary of organic and elemental carbon/black carbon analysis methods and intercomparisons, AAQR, 5, 65-102, 2005.

Welthagen, W., Schnelle-Kreis, J., and Zimmermann, R.: Search criteria and rules for comprehensive two-dimensional gas chromatography-time-of-flight mass spectrometry (GCxGCTOF MS). Analysis of airborne particulate matter., J. Chromatogr. A, 1019, 233-249, 2003.

Williams, B., Goldstein, A., Kreisberg, N., and Hering, S.: An in-situ instrument for speciated organic composition of atmospheric aerosols: thermal desorption aerosol GC/MS-FID (TAG), Aerosol Sci. Tech., 40, 627-638, 2006.

Williams, B. J., Goldstein, A. H., Millet, D. B., Holzinger, R., Kreisberg, N. M., Hering, S. V., White, A. B., Worsnop, D. R., Allan, J. D., and Jimenez, J. L.: Chemical speciation of organic aerosol during the International Consortium for Atmospheric Research on Transport and Transformation 2004: results from in situ measurements, J. Geophys. Res.-Atmos., 112, D10S26, doi:10.1029/2006JD007601, 2007.

Zappoli, S., Andracchio, A., Fuzzi, S., Facchini, M. C., Gelencsér, A., Kiss, G., Krivácsy, Z., Molnár, A., Mészáros, E., Hansson, H. C., Rosman, K., and Zebühr, Y.: Inorganic, organic and macromolecular components of fine aerosol in different areas of Europe in relation to their water solubility, Atmos. Environ., 33, 2733-2743, 1999.

Zhang, J., Kebin, H., Xiaoyan, S., and Yu, Z.: Comparison of particle emmissions from an engine operating on biodiesel andpetroleum diesel, Fuel, 90, 2089-2097, 2011. 